Research Group: Environmental Economics and Natural Resources

\title{
"Cultural investment, local development and instantaneous social capital: A case study of a gathering festival in the South of Italv"
}

GUISEPPE ATTANASI, FORTUNA CASORIA, SAMUELE CENTORRINO, GIULIA URSO 


\title{
Cultural investment, local development and instantaneous social capital: A case study of a gathering festival in the South of Italy
}

\author{
Giuseppe Attanasi - University Paris 1 Panthéon-Sorbonne, France \\ Fortuna Casoria - Maastricht University, the Netherlands \\ Samuele Centorrino - Toulouse School of Economics (GREMAQ), France \\ Giulia Urso - University of Salento, Lecce, Italy
}

February 2012

\begin{abstract}
In this paper we show how the investment in cultural events may encourage the building of social capital and foster the development of local communities. We rely on a casestudy that we conducted about the socio-economic impact of the Festival "La Notte della Taranta", the most important European music festival dedicated to traditional music (about 170.000 participants per year), on the sub-region of southern Italy where it is held. Our evidence is based on a large survey, consisting of nearly 10.000 interviews to Festival participants over a span of five editions (2007-2011). A primary result is that the initial economic investment in the Festival has brought a short-term return in terms of touristic attraction worth more than two times as much. More importantly, our results indicate that a cultural festival, despite being a mass gathering, is able to create strong bonds among its participants and between them and the area where the event takes place. Although these bonds are "instantaneous", i.e. temporally restricted to the duration of the event, they are positively correlated with the economic impact of the event on the territory.
\end{abstract}

JEL classification: A13; O12; Z10.

Keywords: Cultural event; economic impact; social capital; greatly motivated tourist.

- Corresponding author: Centre d'Economie de la Sorbonne, 106 boulevard de 1'Hôpital, 75013, Paris. Email: attanasi@cict.fr. Phone: +33(0)659200132. The research leading to these results has received funding from the European Research Council under the European Community's Seventh Framework Programme (FP7/2007-2013) Grant Agreement no. 230589. The authors gratefully thank Francesco Passarelli, Rita Durante, Nikolaos Georgantzìs and Laura Concina for useful comments and suggestions. 


\section{Introduction}

Financing and organizing cultural events linked to history and traditions of a community can lead to its overall development, due not only to the direct and to the indirect economic impact the tourist flow produces in the short-term. Culture positively affects the behavior of those people who directly and indirectly benefit from the cultural event, promotes the creation of social ties and sets the conditions for a sustainable economic development of the territory. While there is a large literature on the analysis and assessment of the economic impact generated by festivals on the host territory, there are few empirical studies dealing with the socio-cultural effects of this kind of events. In this paper, by means of a field study, we show how the investment in cultural events may encourage the socio-economic development of local communities.

The interactive nature of cultural activities and the relational nature of the cultural goods they produce are the key elements defining the double relationship existing between the promotion of culture and the growth of social capital. The analysis of this supposedly virtuous relationship is getting more and more important due to the increasing attention that governance policies, at different scales, dedicate to the cultural dimension of development. Many local institutions are finally aware that the mutual valorization of the tangible resources of a territory and of the socio-cultural ones may lead to (re)activate the relational mechanisms underlying the processes of local development.

Social capital has become one of the most prolific research areas in economic theory in recent years, although it is still a rather elusive concept: economic theory has not come yet, in fact, to a unique definition (Portes, 1998). It certainly is a form of "capital", since it is a resource bringing with it a kind of utility, and it is "social", as it is not a private property but it belongs to the whole society that benefits from it. As social capital is embedded in the relationships among individuals, it is in fact an invisible and intangible relational resource, which is rooted in social institutions. By encouraging cooperation among individuals, it allows them to more easily reach goals that would be otherwise very expensive or, in extreme cases, impossible to achieve.

The concept of social capital is thus closely related to the concept of trust, with the former being usually interpreted as a direct consequence of the latter. Guiso et al. (2008b) define trust as the subjective probability individuals attribute to the possibility of being cheated. This probability depends on the objective features of the decision setting as well as on the trusting person's subjective characteristics. Alesina and La Ferrara (2002) show that trust in other individuals is (very) positively correlated with income, (a little less) with age, (fairly) with employment, (comparatively few) with education. ${ }^{1}$ Differences in cultural background due to history (Guiso et al., 2004) or religious

\footnotetext{
${ }^{1}$ Butler et al. (2009) highlight the spillover effects in the construction of trust: being cheated by one person in one dimension leads to a downward revision in trust in other dimensions and in other people, too. Further, highly trusting
} 
education (Guiso et al., 2003) are able to create significant discrepancies in the levels of trust between individuals and between countries. Further, the same authors (Guiso et al. 2004, 2006) show that individuals who do not live in their home country tend to "export" the home degree of trust to the place where they currently live. This paper sheds new light on this relation, given that we compare the level of trust of different groups of people during a cultural event, namely, people residing in the region where the event is taking place, tourists who were born in this region and currently living elsewhere and non-native tourists.

The relationship among trust, social capital and culture is intriguing. High-trust societies, inclined to spontaneous sociability not conditioned by the belonging to the same subgroup of stable relationships, are more likely to create social capital than others, as this is intrinsic to their culture. According to Fukuyama (1996), social capital differs from other forms of human capital insofar as it is usually created and transmitted through cultural mechanisms like religion, tradition or historical habit. A system of shared values and traditions as well as the need to assert one's own local identity become strong elements of cohesion and reasons for aggregation and trust among individuals.

One of the assumptions of the analysis undertaken in this paper is that cultural events, when rooted in the cultural background of the place that hosts them, can lead to an increase in trust among participants, and eventually generate social capital: the investment in cultural events may encourage the development of local communities through the building and strengthening of this intangible factor.

We rely on a case study that we conducted over a span of five editions (2007-2011) about the socioeconomic impact of the Festival "La Notte della Taranta", the most important European music festival dedicated to traditional music (about 170.000 participants per year in 2007-2011), on the area where it is held (Province of Lecce, southern Italy). It is an itinerant folk music festival (around 15 concerts in 15 villages very "close" to each other), held once per year during the last three weeks of August. It was born out of the idea of recovering and reviving the traditional repertoire of folk music of the Province of Lecce ("pizzica") linked to the phenomenon of "Tarantism", thus reinforcing identity and cultural specificity of this southern Italian area. Our intuition is that the revival and sharing of this tradition, i.e. the tradition related to "Tarantism" and to its music, have been able, on one side, to support the promotion of the area, through a cultural event now at its $14^{\text {th }}$ edition; on the

individuals think others are like them and tend to form beliefs that are too optimistic, causing them to assume too much social risk and to be cheated more often.

${ }^{2}$ Tarantism is an alleged, possibly deadly envenomation, popularly believed to result from the bite of a kind of wolf spider called "tarantula" (Lycosa tarantula). It was originally described in the eleventh century, though this condition was common in southern Italy during the sixteenth and seventeenth centuries (see Russell, 1979). There were strong suggestions that there is no organic cause for the heightened excitability and restlessness that gripped the victims. The stated belief of the time was that victims needed to engage in frenzied dancing to prevent death from tarantism. Supposedly, a particular kind of dance, called the "tarantella", evolved from this therapy (see Attanasi, 2007). 
other side, they have led to the creation of social capital in the area where the event is held, especially among people attending the Festival. Such a result is even more relevant when acknowledging that the interested area (and South of Italy in general) is poor in this intangible resource.

Our case study indirectly challenges the link between social capital and local resources, i.e. the geographical dimension of social capital. Many sociological studies indicate that usually individuals do not establish their social relationships outside the place and the traditions in which they are immersed. For example, Kan (2007) and David et al. (2010) show that social ties cannot be moved from one place to another: social capital has a spatial nature, it is location-specific. We agree with them that social capital must be first identified and recognized as a resource of a specific place. However, once its local features are duly solicited, it should be placed in contact with the outside, since it cannot remain confined within the boundaries of the local community given its nature of relational resource. Indeed, in this paper we show how a festival arisen from the cultural specificity of the area where it is held may become a driving force to support local development when also tourists attracted to the area by the event identify themselves with its local culture.

Earls (1993) underlines how festivals have the potential for strengthening communal ties and uniting people of different backgrounds. The staging of a festival can develop social capital through different processes. First, by providing the local community with specific opportunities to access and develop its own resources. Second, by generating touristic attraction leading to the connection among people of different cultures. Third, by offering both residents and visitors a motivation for celebration. Finally, by creating social cohesiveness among participants, giving both residents and visitors the impression of belonging to a unique virtual community.

First of all, the production of a festival may have a huge effect in terms of social capital on people residing in the place where it is held, because of the emergence of new socio-economic relationships, prerequisite for the creation of larger networks. As Arcodia and Whitford (2006) correctly state, organizing a festival raises awareness of the community resources and expertise that previously might have remained hidden, produces social links among previously unrelated individuals and generally encourages a stronger interaction among existing community organizations. The social networks that can develop through the organization of festivals have the potential to be maintained far beyond the short life of the event, even though this rarely happens. In the case where festivals are regular events, as in our case study, the place where they are held is supposed to have a far greater long-term benefit from them. Moreover, when a festival has a strong cultural connotation, it may generate even deeper effects, which are more likely to virtuously act on the sense of belonging and on the strengthening of the place identity (Girard, 2008). Cultural festivals stemming from socio- 
cultural aspects that closely relate to the traditions of a place, as in the case of "La Notte della Taranta", identify themselves with the spirit of the community (Getz, 1997; Yeoman et al., 2004) and are expression of the "genius loci", i.e. that heritage resulting from the history of the territory and from the evolution, and sedimentation over time, of its tangible and intangible resources. This heritage is made of those not imitable, non-reproducible peculiarities and symbolic values of a place. The uniqueness is indeed a feature of big events originating from the hallmarks of an area in continuity with its history, perceived as part of a wider cultural heritage which, on that occasion, is made accessible to visitors.

Indeed, the production of a festival may have a huge effect in terms of social capital due to people who choose to visit the place where it is held because of the festival. Positive implications for increasing the level of social capital in a specific area have been widely highlighted with reference to the impacts generated by those forms of tourism linked to heritage, the so called "cultural" or "heritage tourism" (see Girard, 2008). Cultural tourism produces impacts on the different forms of capital (natural, human, and social) increasing, through them, multiplicative effects on local development. On one side, communities that have a strong sense of identity and value their own heritage and lifestyle have a good chance to design a touristic "product" that can be attractive to potential tourists (Macbeth, 1997). On the other side, culture raises awareness about the community's cultural capital, strengthening its identity as well as the bonds between people. Macbeth et al. (2004) detect an important relationship between culture and tourism; they claim that while cultural capital can form the basis for tourism, tourism is in turn likely to enhance and enrich the cultural capital of the community. Nevertheless, traditional views of both local development and local tourism development have focused on economic factors and potential innovation in technical and resource exploitation processes. Tourism development is usually couched in economic terms, such as the level of tourist flow or the number of jobs created. Although in the first part of the paper we provide a measure of the pure economic impact of the Festival due to touristic attraction, we acknowledge that this kind of approach usually ignores the social aspects of tourism development. A central idea of this paper is that social capital and cultural tourism contribute to each other. Social capital can facilitate the promotion of cultural activities that attract visitors and this is the case in our empirical research. The awareness that their place appeals to tourists makes residents proud of their local traditions and heritage and fosters a perception of their own "uniqueness" which in turns facilitates return visits.

Events have a key-role in the activation of these virtuous circles between culture promotion and growth of social capital: being moments of public celebration, they incite local community involvement in the use and enhancement of its heritage, generating civic pride and sense of 
belonging to the place. In this paper we are particularly interested in the increase in social capital that the public celebration offered by a cultural event produces on its participants. The potential to facilitate community celebration is one of the defining characteristics of festivals, especially if they are "culturally bound", given that the phenomenon of celebration itself is intrinsic to all cultures. For local people there is an inherent value in celebration, which consists in the encouragement to take part in the planning and management of socio-cultural activities as a part of the shared life of a community (Schuster, 1995). Consequently, festivals having a celebratory theme are perceived as an occasion that generates a feeling of goodwill or a spirit of "communitas" (Salamone, 2000). They can satisfy local people's desire for sociability and their need for feeling part of a group. Moreover, tourists could go visiting the specific area where the event is held because they perceive the festival attendance as an opportunity to take part in a form of social ritual (Kolb, 1995).

From this perspective, cultural initiatives belonging to the family of "here and now events", are called for an immediate satisfaction of the needs for socio-relational moments, ranging from the pursuit of living a shared experience to the expression of one's own value systems and lifestyle. This directly introduces the last way in which festival attendance can promote social capital, which is by engendering an ever-increasing social cohesiveness among festival participants within the host community (Falassi, 1987). The strategic role of the promotion of cultural events could result in fostering context conditions which are likely to increase the level of economic, social and cultural relationality. These conditions may help strengthen the sense of belonging to the community and to the place even in people who do not reside in or who are not native of this place. The fact that both residents and visitors feel part of the same virtual community attending the festival may lead to the reaffirmation of a shared local identity and to the accumulation of social capital. A festival which is based on the local community values and cultural background may constitute a strong reference point. In this case, therefore, cultural events do not have only a recreational value anymore, but help to reinvigorate civic pride, with positive effects in terms of social cohesion and aggregation.

However, the last two effects of cultural festivals on social capital - namely, the event celebration and the social cohesiveness among participants - are mostly an ephemeral and contingent intangible resource. Being related to the event consumption by the audience, they are limited in time and circumstances. Therefore, we define the additional increase they generate on social capital as "instantaneous".

This is exactly the kind of social capital we focus on in this paper: we measure the amount of additional trust that participants in the Festival "La Notte della Taranta" feel because of the atmosphere of the event and of the sharing of this particular experience. Our evidence, based on a large survey consisting of nearly 10.000 interviews to Festival participants over its five editions 
2007-2011, indicates that a mass gathering, when having a convincing cultural characterization, is able to create strong bonds among its participants and between them and the area where the event takes place. These bonds prove to be virtuous especially when this region happens to be perceived as a cradle of long-lasting and deep-rooted traditions, such as those related to "Tarantism", a phenomenon that nowadays can be found only in few villages within the Province of Lecce and nowhere else. As a consequence, a greater mutual trust arises among the participants in the event. This trust has many specific determinants. In this paper, we isolate and analyze some of them: participants' idiosyncratic features (age, level of education, etc.), some of their personal traits (e.g., risk aversion) and their perception of the Festival. Further, we compare the level of instantaneous social capital perceived by different categories of participants - residents, native tourists and nonnative tourists - and we show that it is higher for tourists who are on vacation in the area where the Festival is held just because of it.

Another contribution of the paper is the assessment of the shock of demand generated by the Festival on the economy of the area where it is held from its beginning to its end (around 3 weeks). The "instantaneous" economic impact of the Festival on the local economy is certainly a restrictive measure of its overall economic effect: long-term potential effects in terms of territory and tourism promotion should be taken into account as well. However, the short-term increase in the touristic demand for local goods and services due to the Festival in the period when it takes place has its own intrinsic value: it represents the lower bound of the overall economic impact that the event generates. Finally, we analyze the correlation between the local economic impact produced by tourists attracted to the area by the Festival in a given edition and the instantaneous social capital they have perceived by participating in that edition.

The rest of the paper is structured as follows. In section 2 we first review the main features of the Festival "La Notte della Taranta", by underlining its cultural aspects. Then, we describe how our field research on this cultural event has been carried out. In section 3 we introduce and discuss the methodology that we followed in order to estimate the local economic agents' short-term revenues coming from tourists attracted by the Festival. Further, we measure the rate of return of the investment in the Festival over the five years 2007-2011 for the local economy that hosted it. In section 4 we measure the impact of the Festival in terms of instantaneous social capital generated on its participants. Moreover, we relate the level of instantaneous social capital obtained in the 20072011 Festival editions to the explanatory variables analyzed in all five years of our survey and to the economic impact of the Festival as measured in section 3. Section 5 concludes. 


\section{Case study: research purpose and methodology}

This section is dedicated to the description of the main features of the Festival "La Notte della Taranta" and of the methodology that we used in order to elicit participants' data, choices and preferences needed to estimate the short-term economic impact of the Festival and the level of instantaneous social capital it was able to generate. In the first part of the section, we briefly review the history, the aims and the structure of this folk music festival, by stressing its main cultural aspects. In the second part, we specify the methodology we followed in order to sample and interview participants during the concerts of the five editions 2007-2011 of the Festival.

\subsection{The Festival "La Notte della Taranta": cultural distinctive features and structure}

The Festival "La Notte della Taranta" was first held in 1998 on the initiative of the nine municipalities of the Grecia Salentina, a linguistic and cultural region within the Province of Lecce where an ancient Greek dialect language known as griko is still spoken by small minorities. Since its first edition in 1998, the Festival has gained in popularity and, starting from 2005, its audience reached more than 100.000 participants per year.

This folk music festival, which is mainly constituted by a traditional musical repertoire called "pizzica salentina", is meant to preserve this language and promote at the same time the local cultural heritage. In the first fourteen editions, the Festival has been an effective means of retrieving and internationally promoting this repertoire, mixing and blending it with other cultures' rhythms and modern musical styles. ${ }^{3}$ The mixture of tradition and contamination characterizing the evolution of the Festival "La Notte della Taranta" has not altered its original meaning: endeavoring to bring together myth and history, symbolically reunified under the logo of the tarantula, the spider whose bite effects were popularly believed to be curable only by dancing (pizzica). ${ }^{4}$ The identity component that inspired and served as a spur to envisage the original concept of the Festival is then the phenomenon of Tarantism: it falls within an ancient and complex belief system which survived until a few decades ago in southern Italy, but not observed nor recorded anymore since many years.

With regard to its structure, the Festival "La Notte della Taranta" consists of two sub-events closely connected to each other: a series of 13-15 itinerant concerts, with the number of participants in each

\footnotetext{
${ }^{3}$ The Festival is a true musical melting pot which, successfully started in the past with the fusion of sounds coming from the Byzantine, the Balkan or the Turkish culture, keeps being attractive nowadays thanks to the original mixture of traditional music with contemporary tunes such as jazz, rock, classical and world music.

${ }^{4}$ Popular belief has it that during the summer harvest, when the spiders are about, the bite of the tarantula drove its victims, mainly women, to a state of unconsciousness to come out of which the healing ritual found the music as main cure. The bite-victims were induced to engage in a frenzied dancing to the beat of a fast-paced therapeutic music, believing that the sweat produced by dancing frantically would release the venom from the body. Recently, the evocative and theatrical representation of this dance has caught on: the "pizzica" and related music genres, combined together with folk beats coming from different cultural backgrounds, are the core element of "La Notte della Taranta".
} 
of these concerts usually ranging between 2.000 and 10.000 people; a subsequent big concert, which concludes the Festival, whose number of participants ranged between 90.000 and 150.000 people in the editions 2007-2011.

The itinerant concerts (henceforth, minor concerts) take place once per day over a time span of about two weeks, from the first half to the end of August. Each concert is held in the main square of one of the villages of the Grecia Salentina - the set of locations being the same each year - with each village being a few kilometers away from all the others. During each of the minor concerts, 3-4 folk music local bands usually perform for about 3 hours in total.

The big sub-event concluding the Festival, namely the Final Concert, is held every year two days after the end of the series of minor concerts. The location is always the main square of the smallest village of the Grecì Salentina, ${ }^{5}$ which in correspondence of this mass gathering turns into a huge dance floor. In the Final Concert, year by year, a Maestro of international fame is called to revise the local repertoire and produce an original yet traditional display of music from the Grecìa Salentina. During the Final Concert many international musicians perform for about 5-6 hours during the night, accompanied by "La Notte della Taranta" Orchestra, which consists of only traditional instruments.

Over the years, the Festival has been evolving along two different tracks: on the one hand, it promotes local music and traditions throughout the region; on the other hand, it succeeds in exporting that music outside the regional borders by attracting tourists and hosting famous musicians of various regions and musical styles.

The case of "La Notte della Taranta" is controversial and it is still extensively discussed from a political point of view. On the one hand, it is seen as capable of stimulating and boosting local cultural and economic development by promoting culture. On the other hand, it represents the heaviest investment in culture and music in the southern-Italian region of Apulia, to which the Province of Lecce belongs. The organization and the realization of the Festival requires huge economic investments, on the part of the local, provincial and regional administration (see section $3.1)$.

\subsection{Research methodology: questionnaire structure and sampling method}

The field research has been carried out by means of guided interviews addressed to a representative sample of participants in the Festival during the concerts of the editions 2007-2011. The interviews were conducted via questionnaires. The questionnaire proposed to the Festival participants has been structured to assess the socio-economic impact of the event on the region where it is held and its sociological effects on people attending the concerts. Hence, the questions interviewees were

\footnotetext{
${ }^{5}$ Melpignano, a village of about 2.000 inhabitants.
} 
presented with were mainly aimed at: collecting information on participants' place of origin and on the role the Festival played in leading those who are not residents in the Province of Lecce to go there on vacation (Part I); appraising the participants' perception of the Festival and of the local social capital (intangible resources, cultural heritage, traditions, etc.), as well as measuring specific idiosyncratic features (age, level of education, etc.), personal traits (e.g., risk aversion) and cultural tastes (Part II). Lastly (Part III), questions on tourism-related indicators, such as average daily expenses, length of stay, services used in the area of vacation, have been introduced. The sequence of questions as well as the list of possible answers to each question was presented in opposite order to half of the sample, so as to check for order effects in the interviewees' answers. Moreover, a series of control questions was introduced in each questionnaire in order to assess the level of attention during the interview and the reliability of the answers provided to our interviewers.

A sample of almost 10.000 participants in the Festival has been interviewed over a span of five editions, from 2007 to 2011. In each of the five editions, the survey period covered the whole duration of the Festival, usually ranging from August 7-13 until August 22-28. During the minor concerts, interviews were conducted by 6-8 graduate students who randomly and independently selected the sample of respondents in different points of the squares where the concerts were held or in adjacent streets. Each interviewer was careful not to interview people from the same group of participants or who had already been interviewed during previous concerts. Interviews were carried out in a time frame of about four hours (from 8:30 pm to 0:30 am and beyond), that is before the beginning (normally set at 9:30 pm) and throughout the concerts (minor concerts last on average four and a half hours). Each interview took from 7 to 10 minutes to be completed, depending on the interviewees being residents or tourists: in the latter case, the interview included additional questions related to the status of tourist (Part III). Given the larger amount of participants in the Final Concert, in this case the number of interviewers involved amounted to $30-35{ }^{6}$ They were divided into two groups: the first one conducted interviews from 6:30 pm to 0:30 am - that is, before the concert started and during its execution - and the second one from 9:30 pm to 3:30 am - that is, during the concert and beyond its end - with the Final Concert normally taking place from 7:30 pm to 2:30 am. Again, in the Final Concert interviewees were randomly and independently selected among the participants in the concert, and people from the same group of participants or who had already been interviewed during the minor concerts were not interviewed.

In order to estimate the number of participants in each concert within a specific edition of the Festival, the data provided by the Local Police or the Traffic Officer Commands of each municipality

\footnotetext{
${ }^{6}$ Given the high number of interviewers needed, we recruited also undergraduate students in Economics and Sociology. During the week before the Final Concert they were appropriately trained on the contents of the questionnaire, on how to randomly select the Festival participants to be interviewed and to conduct a guided interview.
} 
have been crosschecked with the data we personally collected under the guidance of a surveyor usually residing in the municipality where the concert took place. Besides evaluating the full capacity of each of the squares where concerts were held, the stream of people to the places surrounding the site of interest (bars, restaurants, parks) has been assessed as well, and included in the reckoning of participants even though they did not directly attended the concert.

In Table 1 the number of interviews realized during each of the editions 2007-2011 is shown, together with the estimated number of participants in each specific edition of the Festival. We have a total of 9.919 observations, out of about 889.500 participants over five years. The sample representativeness has been controlled for through the Marbach test (Marbach, 2000). ${ }^{7}$ In each sample, the parameter $x$, which provides a measure of the margin of error, is within the tolerance limit of 0.05 : the sample probability oscillates between $95 \%$ and $98 \%$ and, therefore, the sample proved to be representative of the target population. In particular, the number of interviews carried out during the minor concerts and that of interviews realized during the Final Concert turned out to be comparable to each other: both samples are highly representative for all years in the survey.

Table 1 - Population, sample and its representativeness.

\begin{tabular}{llrrrr}
\hline \multirow{2}{*}{$\begin{array}{l}\text { Festival } \\
\text { Editions }\end{array}$} & \multirow{2}{*}{ Sub-events } & $\begin{array}{c}\text { Estimated } \\
\text { Population }\end{array}$ & $\begin{array}{c}\text { Sample } \\
\text { Size }\end{array}$ & $\begin{array}{c}\text { Margin of error } \\
x=\sqrt{\frac{N}{(N-1) n}-\frac{1}{N-1}}\end{array}$ & $\begin{array}{c}\text { Sample } \\
\text { Probability }\end{array}$ \\
\cline { 5 - 6 } \multirow{2}{*}{2007} & minor concerts & 68.000 & 2.172 & 0,02 & $98 \%$ \\
& Final Concert & 100.000 & 704 & 0,04 & $96 \%$ \\
\hline \multirow{2}{*}{2008} & minor concerts & 71.500 & 483 & 0,04 & $96 \%$ \\
& Final Concert & 150.000 & 416 & 0,05 & $95 \%$ \\
\hline \multirow{2}{*}{2009} & minor concerts & 65.000 & 2.596 & 0,02 & $98 \%$ \\
& Final Concert & 100.000 & 1.000 & 0,03 & $97 \%$ \\
\hline \multirow{2}{*}{2010} & minor concerts & 60.000 & 427 & 0,05 & $95 \%$ \\
& Final Concert & 100.000 & 1.000 & 0,03 & $97 \%$ \\
\hline \multirow{2}{*}{2011} & minor concerts & 85.000 & 357 & 0,05 & $95 \%$ \\
& Final Concert & 90.000 & 764 & 0,04 & $96 \%$ \\
\hline
\end{tabular}

Notice that the administrative bodies provided us with disaggregated data by minor concert, which included individuals who took part in many concerts within the same edition of the Festival. This implies that the actual number of participants in each edition taken as a whole is overestimated, since data are aggregated by counting a given individual as many times as the number of concerts he attended. In the next section, when estimating the economic impact of the Festival, we will recalculate all attendance-related data by discounting the population of participants according to the

\footnotetext{
${ }^{7}$ The Marbach test associates the pair of variables $N$ (size of the target population) and $n$ (sample size) with a parameter $x$ that specifies the tolerated amount of margin of error occurring when the sample of size $n$ is taken as representative of the whole population. In the literature, values of $x$ lower than 0.05 are normally seen as acceptable.
} 
number of those interviewees who asserted that at the time of the interview they had already taken part in other concerts within the same edition of the Festival.

In the next two sections we use the data from our field research in order to estimate the short-term economic impact of the Festival on the local area (section 3) and its capability to generate trust and social capital among its participants (section 4). In both sections, we distinguish different categories of participants in the Festival. The reference category is the one of residents or Locals, i.e. participants who permanently or for the most part of the year reside in the area where the Festival is held, the Province of Lecce. We define as tourists those participants who do not permanently reside in the Province of Lecce but at the time of the interview are in the Province of Lecce for any reason (work, vacation, family or friends). Inside this category, we distinguish between native tourists participants who were born in the Province of Lecce but live somewhere else - and non-native tourists - participants who were born outside the Province of Lecce. Inside the latter category, we distinguish among participants who are on summer vacation in the Province of Lecce for reasons other than the Festival, those who are there also for the Festival (in part motivated tourists) and those who are there just because of the Festival (greatly motivated tourists). Notice that while in the category "tourists" we include also people who are in the Province of Lecce to work or visit relatives and friends, only those tourists who are there on vacation can belong to the "in part" or to the "greatly" motivated tourists groups.

While in the analysis of the social capital generated by the Festival we take into account and compare all the categories introduced above, in the measurement of its economic impact we restrict our attention only to greatly and in part motivated tourists.

\section{The "Istantaneous" Economic Impact of the Festival}

In this section, we focus on the cost-benefit analysis of the Festival. In particular, we estimate the impact on the local economy of the increase in demand generated by tourists. Further, we measure the rate of return of the public/private investment in the Festival for the local economy that hosted it over the five years 2007-2011. In this paper we rely only on short-term indexes, since they take into account only the increase in tourists' demand for local goods and services due to the Festival in the period in which it takes place (last three weeks of August).

\subsection{Costs of the Festival}

The Festival "La Notte della Taranta" requires huge both public and, to a lesser degree, private investments. Here we analyze the costs the Festival entails, and classify them according to two 
variables:

- their nature, distinguishing between expenses for music performers and "other expenses". Expenses for music performers relate to the fees paid out to all artists performing in the concerts, while "other expenses" refer to all costs born to organize, manage and advertise the event;

- the specific sub-event they refer to, distinguishing between expenses for the minor concerts and expenses for the Final Concert. Here expenses that are common to both sub-events (e.g. advertisement of the Festival, management of the event website) have been equally shared between the two sub-events.

The costs of the Festival for the editions 2007-2011 are summarized in Table $2,{ }^{8}$ classified according to the two above-mentioned variables.

Table 2 - Costs of the Festival (in $€$ ), classified according to nature and sub-events.

\begin{tabular}{|c|c|c|c|c|c|}
\hline & \multicolumn{2}{|c|}{ Nature $(\mathbf{N})$} & \multicolumn{2}{|c|}{ Sub-event $(\mathbf{S})$} & \\
\hline $\begin{array}{l}\text { Festival } \\
\text { Editions }\end{array}$ & $\begin{array}{l}\text { Music performers } \\
\left(\mathbf{N}_{1}\right)\end{array}$ & $\begin{array}{l}\text { Other expenses } \\
\qquad\left(\mathbf{N}_{\mathbf{2}}\right)\end{array}$ & $\begin{array}{c}\text { minor concerts } \\
\left(\mathbf{S}_{\mathbf{1}}\right)\end{array}$ & $\begin{array}{l}\text { Final Concert } \\
\qquad\left(\mathbf{S}_{\mathbf{2}}\right)\end{array}$ & $\begin{array}{c}\text { Festival } \\
\left(\mathbf{N}_{1}+\mathbf{N}_{2}\right)=\left(\mathbf{S}_{1}+\mathbf{S}_{2}\right)\end{array}$ \\
\hline 2007 & 401.015 & 783.540 & 355.366 & 829.189 & 1.184 .555 \\
\hline 2008 & 260.440 & 661.128 & 276.470 & 645.098 & 921.568 \\
\hline 2009 & 228.710 & 578.149 & 242.058 & 564.801 & 806.859 \\
\hline 2010 & 300.000 & 650.000 & 285.000 & 665.000 & 950.000 \\
\hline 2011 & 270.000 & 600.000 & 261.000 & 609.000 & 870.000 \\
\hline $2007-2011$ & 1.460 .165 & 3.272.817 & 1.419 .894 & 3.313.088 & 4.732 .982 \\
\hline
\end{tabular}

Over the fourteen editions of the Festival organized up to now (1998-2011), the last five editions are characterized by the highest costs and public/private investments. Over the five-year time span we analyzed, the Festival has been mostly financed by the region of Apulia and the municipalities belonging to the Grecia Salentina, which together covered at least $40 \%$ of the cost each year (in edition $2010,80 \%$ of the financing has been provided by these two public institutions). However, besides being financed by public institutions, the event also benefits from the economic support of private local firms, even though the latter contribute to a lesser degree (between $15 \%$ and $25 \%$ of the whole cost).

Table 2 shows that the edition where the costs have been the highest (2007) accounts for $25 \%$ of the almost 5M\$ invested in the last five years. The overall cost of the event decreased over the last four editions due to reduced funds raised. In particular, with respect to 2007 , costs for music performers have been reduced on average by $35 \%$ over the last four editions while the proportion of "other expenses" over the costs for music performers has been growing in editions 2008-2009 (2.5 times vs

\footnotetext{
${ }^{8}$ All data included in Table 2 come from official documents: we got them from the festival organizational structure and from the institutions which finance it. The data of the last two editions have not been made public yet so we got the only official rounded total cost of the Festival instead of the details for each item of expenditure as for the previous editions.
} 
2 times), and got back to the initial level in the last two editions. Conversely, the share of the investments allocated to the minor concerts and to the Final Concert has been kept constant over the whole considered time period (30\% and $70 \%$, respectively). Therefore, the larger expenses in the 2007 edition were mainly due to the larger investment in the Final Concert. We will go back to this point when investigating the economic impact of this investment in the subsequent editions.

\subsection{Methodological issues about the estimation of local economic impact}

In this paragraph we describe and discuss the methodology we used to calculate the shock of demand generated by the Festival on the economy of the municipalities within the Province of Lecce, in the period ranging from the second to the last week of August over the years 2007-2011.

We acknowledge that it is quite restrictive to study the economic impact produced by the Festival by only focusing on the period during which it takes place: long-term potential effects in terms of territory and tourism promotion have to be taken into account as well. However, the instantaneous impact on the local economy has its own intrinsic value: it represents the lower bound of the overall economic impact that the event generates.

Hence, we aim at determining $X$ and $Y$ so that the following conclusion can be drawn: (a) "given an investment equal to $X €$, the Festival yields wealth at least amounting to $Y €$ ", where $Y$ can be greater than, less than or equal to $X$. Furthermore, we would like to shed some light on what the short-term consequences would be if the Festival were not held in a given year, i.e. to determine $Z$ so to be able to conclude that: (b) "if in year $t$ the Festival had not been organized (by saving $X €$ ), an economic loss of at least $Z €$ would have been suffered in $t$, with $Z$ greater than, less than or equal to $X$ '. In order to get to conclusions (a) and (b), we first need to consider two preliminary issues.

The first one is related to the macro analysis of the assimilation of the demand generated by the Festival, which should be satisfied by the local economic system. We therefore distinguish between direct effects of the Festival on those economic sectors that ought to absorb this transitory increase in demand, and indirect or induced effects on those sectors that are not directly involved but receive positive spillovers from other economic actors. This issue is tackled via an input-output (IO) analysis (Leontief, 1986).

The second matter deals with the micro analysis of the characterization of this demand. A strict input/output analysis requires that we consider only expenditure of tourists who do not come from the region into consideration (Sheldon 1990, p. 29). Therefore, in our analysis we do not contemplate native tourists, although many of them declare that they go back to their birthplace also because of the Festival: we cannot be sure, indeed, that these tourists would spend the month of August in the Province of Lecce to attend the Festival in the absence of their friendly and family ties. Nonetheless, 
during summer holidays the Province of Lecce is one of the main destinations in Italy of non-native tourists for reasons other than the Festival itself (e.g., beautiful landascape). Thus, within the category of non-native tourists, we restrict our focus to two sub-categories. The first one includes those tourists who declare to go to the Province of Lecce just because of the Festival (greatly motivated). The second one includes those who go also because of the Festival, but would not go if the Festival were not held (in part motivated). In the following, we often refer to Visitors as belonging to one of these two sub-categories, the only ones that we take into account when assessing the surplus in demand generated by the Festival. By considering the category of greatly motivated, we can derive a conclusion of type (a). Thus, we use this group to delimit the lower bound of the economic impact of the Festival. By adding the specific subgroup ${ }^{9}$ of in part motivated to the greatly motivated subjects, we can produce conclusion of type (b), that is we can estimate the lower bound of profits that can be lost if the Festival were cancelled.

Let us now focus on the former macro issue. IO tables are economic instruments that permit to record the structure of the economic system and detect the relation between sectors. These tables consist of three main matrices: the Matrix of Intermediate Demand, which describes the exchanges between different economic sectors; the Matrix of Primary Inputs, which describes returns from labor and capital; and the Matrix of Final Demand, which describes the amount of resources not consumed by the economic system itself. The IO analysis is based only on the Matrix of Intermediate Demand, as it reflects interdependencies between economic sectors. Each element of this matrix, say $x_{i j}$, represents the sales that sector $i$ makes to sector $j$. From this, it is possible to compute the socalled Inverse Matrix of Leontief, whose elements, denoted by $l_{i j}$, give the productive effort which is necessary for sector $i$ to satisfy an increase of one unit in the demand of sector $j$. This implies that the overall effect of an increase in the demand in sector $j$ is given by the sum of the $j$-th column of the Inverse Matrix. Thus, define $M_{i j}=\sum_{i j} l_{i j}$, which is the multiplier of demand for sector $j$. The first step of this macro analysis (also called non-survey) is therefore to obtain the Matrix of Intermediate Demand for the Province of Lecce.

A couple of caveats are in order. First, an official IO matrix is not available either for the Province of Lecce or for the Region of Apulia. Moreover, Apulia is one of the few Italian regions that lack an economic analysis based on the IO technique. Second, the region of Apulia is located in the South of Italy, which is an Objective 1 region for the EU. This has to be taken into account to properly compute the matrix multipliers, as its capacity to satisfy an increase in demand is limited and needs to be addressed with resources coming from neighboring regions or countries.

\footnotetext{
${ }^{9}$ As it will be explained later, we only consider those in part motivated tourists who would not have gone on vacation to the Province of Lecce if the Festival had not been held.
} 
Given the lack of existing IO analyses, we started ours from the IO matrix for Italy in $2000 .{ }^{10}$ Once we obtained the matrix for Italy, we first regionalized it to obtain the matrix for Apulia. This has been done by using available data on supply and use by sector in 2005 . The basic hypothesis is that the regional economy reflects the national relationship between supply and use in different sectors (Stäglin, 1972; 1973). Finally, we discounted the matrix for Apulia to obtain multipliers for the Province of Lecce. Discount rates have been computed using the Simple Location Quotients: for each sector, we derived its relative importance with respect to the economy of the Province of Lecce and we compared it with the regional level. If the former is higher than the latter, then that particular sector is immediately able to satisfy the local/internal demand; otherwise, the local area will need to import to satisfy the new increase in the demand. A full comparison between the matrix multipliers by sector for Italy and for the Province of Lecce can be found in Table A.2 in the Appendix. We believe that our multipliers describe well enough the latter economy, which is well below the national average.

Once we have obtained the multipliers for every sector, we computed the demand shock generated by the Festival. To evaluate the shock impact, we used the "Money Generation Money 2" model (Styne et al., 2000). This model assumes that the economic impact is given by the following relation:

\section{Economic Impact $=$ No. of Visitors * Average Daily Expenditure per Visitor * * Average Duration of Stay * Economic Multipliers}

The need to calculate the average expenditure per visitor brings us back to the second matter of the analysis: how to properly identify those tourists accounting for the increase in demand generated by the Festival? In this regard, we used a micro analysis (so-called survey), based on the interviews we made to people attending the Festival in the editions 2007-2011 (see section 2.2). First of all, the survey analysis enabled us to compute the percentage of non-native tourists within the population (see Table A.1 in the Appendix). However, non-native tourists are among those who granted interviews more frequently. Therefore, we also recorded the place of origin of those people who refused to answer the questionnaire, in order not to overestimate the presence of non-native tourists. Second, the survey analysis allowed us to disentangle greatly motivated and in part motivated tourists (namely, visitors) from other categories of non-native tourists and all other sorts of Festival participants (e.g., residents and people who are in the Province of Lecce for other reasons than the Festival). ${ }^{11}$ Further, through our guided interviews we were able to reconstruct the length of the visitors' stay and their expenditure profile.

We divided visitors into three subcategories, according to the length of their stay in the Province of

\footnotetext{
${ }^{10}$ This matrix is freely available for download on the ISTAT (Italian Institute of Statistics) website, www.istat.it.

${ }^{11}$ See Table A. 1 in the Appendix.
} 
Lecce throughout the period of the Festival: short stay (3 days), medium stay (5 days), and long stay (7 or more days). ${ }^{12}$ As for the expenditures, we asked visitors to assess their expenses for the following four services: Accommodation, Food, Bar \& Pubs, and Transportation. ${ }^{13}$ Then, with reference to Table A.2 in the Appendix, we attributed the total increase in demand to: sector H, when it is due to (an increase in) Accommodation and Food expenses; sector P, if it is due to (an increase in) Bar \& Pubs expenses; sector G, when it is due to (an increase in) Transportation expenses. Before discussing the results of our analysis, we need to consider two other particular aspects of the Festival "La Notte della Taranta".

The Festival is not a unique time or space limited event: as already pointed out, it is held during the last three weeks of August in many different villages of the Province of Lecce, a few kilometers away from each other. There is a high probability of a non-native tourist participating in two or more concerts. Thus, we discounted the total increase in demand by the average probability of participating in at least another concert during the Festival, in addition to the one where the interview took place (subjects were asked to indicate whether, at the time of their interview, they had already participated or intended to participate in other concerts of the Festival). By means of a probit regression model, we evaluated the average probability of participating in more than one concert depending on the status of the subject (resident, native tourist and non-native tourist), age, length of the stay (short, medium, long), motives for the stay (greatly or in part motivated) and on the fact of being interviewed during the Final Concert or not (Table A.6 in the Appendix shows estimates of the average probability of participating in more than one concert of the Festival).

Given our data, the probability of participating in at least another concert of the Festival varies between $10 \%$ and $50 \%$. We can observe that the longer the stay in the Province of Lecce during the last three weeks of August, the higher the probability of participating in more than one concert. Moreover, this probability is higher when the interview took place during the minor concerts of the Festival than during the Final Concert, and it is higher for those who visited the Province of Lecce in part because of the Festival than for those who arrived just because of the Festival.

A further factor has to be taken into consideration when trying not to overestimate the economic impact of the Festival. Even though the touristic demand is generated within the area we are considering, part of the extra revenues created by the increase in expenditure(s) might depart from the area and increase profits of firms located outside the Province of Lecce. It is important, then, to calculate the interdependence (or capture) rate of the economic facilities of the area with respect to

\footnotetext{
${ }^{12}$ See Table A.3 in the Appendix.

${ }^{13}$ See Table A.4 and Table A.5 in the Appendix. The former presents the average daily expenses of greatly motivated and in part motivated tourists. The latter disentangles this variable according to the services these tourists bought in the Province of Lecce and to the duration of their stay in this Province during the period of the Festival.
} 
the neighborhood. In particular, our study mainly considers food and catering sectors that, typically, are accessed by wholesalers who sell products which are not produced in the area (e.g. beer, liquors and other drinks); and the transport sector, which uses resources and produces revenues often outside the area. For these reasons, we decided to apply a capture rate of $72 \%$, based on the weight of imports over total use. This rate highlights a strong interdependence of the sectors we consider, which seems reasonable given the considerations made on the economic performance of the Province of Lecce as compared with the Italian economy as a whole.

To summarize, the impact of non-native tourists' expenditure on the Province of Lecce is calculated as follow:

Economic Impact $=$ No. of Visitors $*(1-p) *$ Interdependence rate * Average Daily Expenditure per Visitor * * Average Duration of Stay * Economic Multipliers

where $p$ is the probability of participating in at least an additional concert of the Festival. ${ }^{14}$

\subsection{Short-term revenues and Return on Investment in the Festival}

In each of the five editions 2007-2011 of the Festival, greatly (in part) motivated tourists amounted on average to more than 20.000 (30.000), with a standard deviation equal to $3.437(5.592) .{ }^{15}$

Table 3 shows data on the economic impact generated by the total expenditure (in euro) of greatly motivated tourists. The total amount of the touristic expenditure in the Province of Lecce of greatly motivated tourists, together with the indirect demand that it generated, represents the information we need to find the conclusion of type (a). Hence, the minimum impact of the Festival amounts to more than $12 \mathrm{M} €$, against a total cost slightly greater than $4.5 \mathrm{M} €$.

Table 3 - Economic Impact (in $€$ ) of the Festival due to greatly motivated tourists.

\begin{tabular}{|c|c|c|c|c|c|}
\hline & \multicolumn{2}{|c|}{ Level (L) } & \multicolumn{2}{|c|}{ Sub-event $(\mathbf{S})$} & \\
\hline $\begin{array}{l}\text { Festival } \\
\text { Editions }\end{array}$ & $\begin{array}{c}\text { Direct impact } \\
\left(\mathbf{L}_{\mathbf{1}}\right)\end{array}$ & $\begin{array}{c}\text { Indirect impact } \\
\left(\mathbf{L}_{\mathbf{2}}\right)\end{array}$ & $\begin{array}{c}\text { minor concerts } \\
\left(\mathbf{S}_{\mathbf{1}}\right)\end{array}$ & $\begin{array}{c}\text { Final Concert } \\
\left(\mathbf{S}_{\mathbf{2}}\right)\end{array}$ & $\begin{array}{c}\text { Festival } \\
\left(\mathbf{L}_{1}+\mathbf{L}_{2}\right)=\left(\mathbf{S}_{1}+\mathbf{S}_{2}\right)\end{array}$ \\
\hline 2007 & 1.923 .849 & 591.865 & 783.011 & 1.732 .703 & 2.515 .714 \\
\hline 2008 & 3.006 .628 & 960.501 & 1.346 .716 & 2.620 .413 & 3.967 .129 \\
\hline 2009 & 1.291 .002 & 477.945 & 321.812 & 1.447 .135 & 1.768 .947 \\
\hline 2010 & 1.626 .461 & 569.387 & 569.313 & 1.626 .535 & 2.195 .848 \\
\hline 2011 & 1.320 .935 & 471.018 & 624.976 & 1.166 .977 & 1.791 .953 \\
\hline 2007-2011 & 9.168 .875 & 3.070 .716 & 3.645.828 & 8.593 .763 & 12.239.591 \\
\hline
\end{tabular}

Table 4 shows data on the economic impact generated by the total expenditure (in euros) of in part motivated tourists.

\footnotetext{
${ }^{14}$ By "Visitor" we mean the non-native tourist who is in the Province of Lecce during the last three weeks of August only (or also) for the Festival

${ }^{15}$ Estimated data on the attendance of greatly motivated and in part motivated tourists can be found in Table A.1 in the Appendix.
} 
Table 4 - Economic Impact (in €) of the Festival due to in part motivated tourists.

\begin{tabular}{|c|c|c|c|c|c|}
\hline & \multicolumn{2}{|c|}{ Level (L) } & \multicolumn{2}{|c|}{ Sub-event $(\mathbf{S})$} & \\
\hline $\begin{array}{l}\text { Festival } \\
\text { Editions }\end{array}$ & $\begin{array}{c}\text { Direct impact } \\
\left(\mathbf{L}_{1}\right)\end{array}$ & $\begin{array}{c}\text { Indirect impact } \\
\left(\mathbf{L}_{\mathbf{2}}\right)\end{array}$ & $\begin{array}{c}\text { minor concerts } \\
\left(\mathbf{S}_{1}\right)\end{array}$ & $\begin{array}{c}\text { Final Concert } \\
\left(\mathbf{S}_{2}\right)\end{array}$ & $\begin{array}{c}\text { Festival } \\
\left(\mathbf{L}_{1}+\mathbf{L}_{2}\right)=\left(\mathbf{S}_{1}+\mathbf{S}_{2}\right)\end{array}$ \\
\hline 2007 & 3.201 .308 & 1.051 .160 & 2.461 .348 & 1.791 .120 & 4.252 .468 \\
\hline 2008 & 6.881 .704 & 2.274 .680 & 4.175 .572 & 4.980 .812 & 9.156 .384 \\
\hline 2009 & 3.655 .293 & 1.244 .491 & 2.052 .834 & 2.846 .950 & 4.899 .784 \\
\hline 2010 & 3.651 .038 & 1.227 .712 & 2.129 .841 & 2.748 .909 & 4.878 .750 \\
\hline 2011 & 3.774 .297 & 1.264 .711 & 2.198 .773 & 2.840 .235 & 5.039 .008 \\
\hline $2007-2011$ & 21.163 .640 & 7.062 .754 & 13.018 .368 & 15.208 .026 & 28.226 .394 \\
\hline
\end{tabular}

As it can be noticed from Table 3 and Table 4, both the minor concerts and the Final Concert generated the highest aggregate economic impact in the 2008 edition.

This is probably due to the large investment made in the Final Concert of the 2007 edition (see Table 2 above). After the 2008 edition, the economic investment in the Festival has been decreasing and the positive shock resulting from the large investment made in 2007 has rapidly disappeared from 2009 onward. However, there is a difference between the economic effect produced by greatly motivated tourists and that generated by in part motivated ones. The positive effect of the huge investment in the 2007 edition of the Final Concert has produced an immediate effect on the number of greatly motivated tourists participating in this sub-event in 2007 and in both sub-events in the next edition of the Festival. ${ }^{16}$ From 2009 onward, the delayed effect of the 2007 investment can still be found in the increased number of non-native tourists going (or going back) to the Province of Lecce in August also because of the Festival.

By summing up the economic impact data in Table 3 and in Table 4, we would obtain the direct and indirect effect of the total expenditure of non-native tourists in the Province of Lecce because of the Festival. However, these data do not represent the real economic impact of the Festival. In part motivated tourists, in principle, could have visited the area even if the Festival had not been organized. This is why we consider only the sub-category of in part motivated tourists who would not have spent their summer vacation in the Province of Lecce if the Festival had not taken place. ${ }^{17}$ Table 5 has been constructed by disentangling the direct and indirect effect of the demand generated only by this sub-group of in part motivated tourists. ${ }^{18}$

\footnotetext{
${ }^{16}$ Table A.1 in the Appendix shows that in the five editions analyzed the number of greatly motivated tourists in the Final Concert is highest in 2007, while in the minor concerts is highest in 2008.

${ }^{17}$ Table A.9 in the Appendix shows, for each Festival edition and for each sub-event, the discount factors we used in order to identify the number of in part motivated tourists who would have not come if the Festival were not held. These discount factors have been calculated according to the answers given by in part motivated tourists in a related question in the interview.

${ }^{18}$ A more detailed version of Table 3, Table 4 and Table 5, respectively Table A.7, A.9 and A.10 can be found in the Appendix. In these tables also the direct and the indirect economic effect specific for the minor concerts and for the Final Concert is presented.
} 
Table 5 - Economic Impact (in $€$ ) of the Festival due to in part motivated tourists who would have not come if the Festival were not held.

\begin{tabular}{|c|c|c|c|c|c|}
\cline { 2 - 5 } \multicolumn{1}{c|}{} & \multicolumn{2}{c|}{ Level $(\mathbf{L})$} & \multicolumn{2}{c|}{ Sub-event $(\mathbf{S})$} & \multicolumn{1}{c|}{} \\
\hline $\begin{array}{c}\text { Festival } \\
\text { Editions }\end{array}$ & $\begin{array}{c}\text { Direct impact } \\
\left(\mathbf{L}_{\mathbf{1}}\right)\end{array}$ & $\begin{array}{c}\text { Indirect impact } \\
\left(\mathbf{L}_{\mathbf{2}}\right)\end{array}$ & $\begin{array}{c}\text { minor concerts } \\
\left(\mathbf{S}_{\mathbf{1}}\right)\end{array}$ & $\begin{array}{c}\text { Final Concert } \\
\left(\mathbf{S}_{\mathbf{2}}\right)\end{array}$ & $\begin{array}{c}\text { Festival } \\
\left(\mathbf{L}_{\mathbf{1}}+\mathbf{L}_{\mathbf{2}}\right)=\left(\mathbf{S}_{\mathbf{1}}+\mathbf{S}_{\mathbf{2}}\right)\end{array}$ \\
\hline 2007 & 358.171 & 118.498 & 369.202 & 107.467 & $\mathbf{4 7 6 . 6 6 9}$ \\
\hline 2008 & 719.361 & 238.034 & 459.313 & 498.082 & $\mathbf{9 5 7 . 3 9 5}$ \\
\hline 2009 & 365.529 & 124.449 & 205.283 & 284.695 & $\mathbf{4 8 9 . 9 7 8}$ \\
\hline 2010 & 426.676 & 143.666 & 212.984 & 357.358 & $\mathbf{5 7 0 . 3 4 2}$ \\
\hline 2011 & 615.753 & 207.434 & 439.755 & 383.432 & $\mathbf{8 2 3 . 1 8 7}$ \\
\hline $\mathbf{2 0 0 7 - 2 0 1 1}$ & $\mathbf{2 . 4 8 5 . 4 9 0}$ & $\mathbf{8 3 2 . 0 8 1}$ & $\mathbf{1 . 6 8 6 . 5 3 7}$ & $\mathbf{1 . 6 3 1 . 0 3 4}$ & $\mathbf{3 . 3 1 7 . 5 7 1}$ \\
\hline
\end{tabular}

The sum of the economic impact for greatly motivated tourists (Table 3) and the economic impact for the in part motivated non-native tourists, who would have not come if the Festival had not taken place (Table 5) represents the information we need to find the conclusion of type (b): if the Festival had not been organized in the five years 2007-2011, public and private sponsors would have saved slightly more than $4.5 €$, but the local area would have lost earnings amounting to at least $15.5 \mathrm{M} €$.

We now turn our attention to the evaluation of the return on investment of the Festival. In other words, we want to know what is the overall economic impact by considering the amount of money invested in the Festival. Thus, we computed the return on investment (henceforth, ROI) for, respectively, the minor concerts, the Final Concert and the overall Festival. The ROI is the ratio of net profits to investments. The former have been computed as the difference between the overall economic impact of the Festival (or one of its sub-events: minor concerts, Final Concert), as resulting from Tables 3 and 5, and its investment (or of one of its sub-events), as resulting from Table 2.

Figure 1 - ROI (Return on Investment) in minor concerts, Final Concert and Festival.

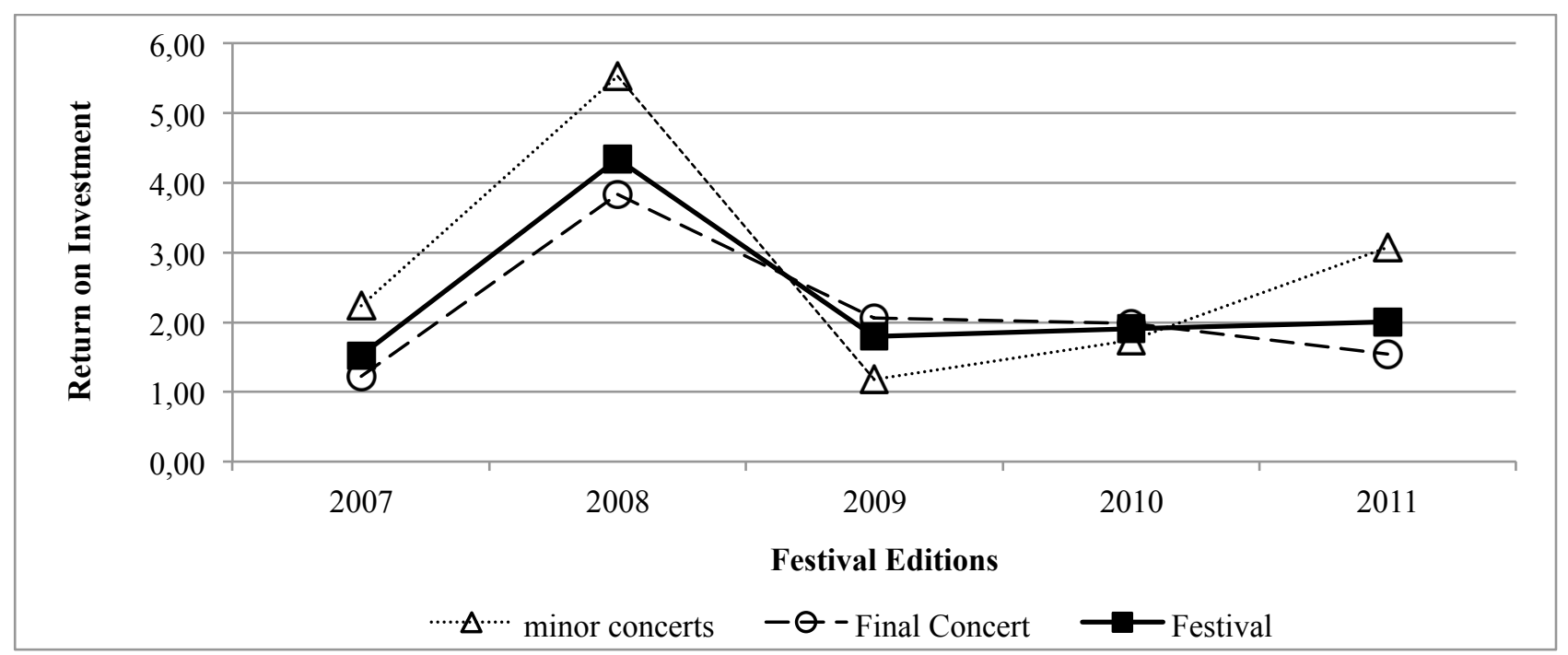

It is worth noticing some important aspects that emerge from this analysis. First of all, the ROI on 
the Festival is extremely high: it yielded a return of 229\%, on average in the five editions analyzed. In three out of the five editions of the Festival the ROI was higher for the minor concerts $(276 \%$ on average over the five editions) as compared to the Final Concert ( $209 \%$ on average over the five editions).

On the one hand, the Final Concert has always been perceived as the driving event of the Festival (both for the image and for the economic impact) and, in fact, its returns are in absolute value higher than those observed in the minor concerts. On the other hand, it is interesting to notice that, in the first two years we considered, the minor concerts produced higher return rates than the Festival itself, despite the huge investment in it, and mainly in the Final Concert, made in 2007 (see Table 2). The impact of this large investment has been captured by the minor concerts in 2008, when the return on the investment of 553\% more than doubled as compared to the previous year (however, also the Final Concert benefited from it as well). The success generated by the image, the advertisement and wordof-mouth advertising in 2007 probably led non-native tourists, in the subsequent edition, to go to the Province of Lecce in order to participate in the whole Festival, and not only in the Final Concert. In 2008, these tourists arrived in the Province of Lecce (much) before the date of Final Concert, enjoying also the minor concerts.

The trend inversion of the ratio of the ROI in the Final Concerts to the one in the minor concerts in the following two editions can be due to lower investments in the Festival in 2008 (see Table 2). It seems, in fact, that minor concerts are much more sensitive to changes in the total amount invested to organize the Festival. This is possibly related to the fact that the investment in year $t$ has a big impact on the number of in part motivated tourists going to the Festival in year $t+1$ : greatly motivated tourists go to the Festival whatever the fame and the number of musicians invited, while these variables - positively related with the amount of investment - are crucial for in part motivated tourists. Indeed, the ratio of the number of in part motivated over greatly motivated tourists is three times as much in the minor concerts than in the Final Concert (see Table A.1 in the Appendix). And our data show that, on average, a partly motivated tourist produces a higher economic impact than a greatly motivated one because of his/her greater length of stay, with this last variable being maximal for in part motivated tourists attending the minor concerts.

Finally, by comparing Table 2 to Figure 1, we notice that a non-increasing relation between the amount invested in the Festival and the ROI emerges. As a matter of fact, the most expensive edition (2007) is also the one that generated the lowest ROI for the overall Festival (153\%). However, we believe that the higher investments undertaken in 2007 had some positive spillover effects in the next years, with a decreasing intensity but strong enough to endure for the next four years. 


\section{Social Capital Impact}

In this section we measure the impact of the Festival "La Notte della Taranta" in terms of instantaneous social capital generated over its participants. In the first paragraph we present and discuss the method we adopted for this measurement. In the second paragraph, we analyze our empirical results on the instantaneous social capital generated by the Festival over the five editions 2007-2011. In this regard, we use a probit regression model to analyze the effect of idiosyncratic, psychological and sociological explanatory variables on the elicited level of instantaneous social capital. Finally, we relate our results on the instantaneous social capital to the short-term economic impact of the Festival as measured in section 3.

\subsection{Some methodological hints on social capital measurement}

Social capital has become one of the most prolific research areas in economic theory in recent years. Nevertheless, as specified in the introduction of the paper, economic theory has not come yet to a unique definition for it. However, a series of empirical studies has been realized on social capital starting from three main definitions (Durlauf, 2002). The first one is by Fukuyama (1999), who classifies social capital as a set of informal values or norms shared among members of a group that permits them to cooperate with one another. The second one, also focusing on the concept of trust, is by Bowles and Gintis (2000), who define social capital as the willingness to behave according to the norms of a community and to punish those who do not. The last definition, which expresses the concept of social capital produced not only by mutual trust, but also by people's interaction, is by Putnam (2000). He specifies that social capital refers both to connections among individuals (social networks) and to the norms of reciprocity and trustworthiness that arise from them.

At first sight, the last definition seems particularly suited to our case study, though the trust emerging during the concerts of a Festival is not embedded into networks or within the connections of a structured organization. It is true that some kind of interactions spontaneously originate among people taking part in a cultural event. However, these interactions are presumably short-lived and trust emerges because of the glue among people sharing some moments of "community" for a given as well as short amount of time.

Our measure of social capital focuses on this specific instantaneous trust. We asked every interviewee in a specific concert of the Festival "La Notte della Taranta" whether a person he/she does not know, for the mere fact of participating that evening at the same concert of the Festival he/she is participating in, deserves to be trusted more than another one he/she does not know and which is not there at that time. Our question therefore aims at extracting a form of trust that is generated by the mere fact of taking part in a shared experience and that could soon evaporate the 
same instant this experience ends (in this sense, it would be "instantaneous" both in its formation and in its expiration). Arguably, such kind of trust rests upon the fact that people feel they know other people within the audience better by realizing they have similar tastes given that they are sharing the same "cultural" experience. This specific form of social capital consists in the reduction of that lack of information which generally discourages people from trusting other people: knowing that a person shares something "special" with me (i.e., a unique cultural experience), and that this sharing is the result of a deliberate "choice" of both of us (we are not at the Festival by chance), reduces the information gap and makes me believe I know at least something about him/her preferences, something crucial. This allows me to trust him/her. My trust can last for the duration of the event only or for a longer time. ${ }^{19}$

The questionnaire proposed during the editions 2010 and 2011 included two more questions aimed at measuring a more general kind of trust. Following Guiso et al. (2008a, 2008b) approach, the first question asks: "Generally speaking, do you think that most people can be trusted or that «distrust(ing) is better»?". Subjects were asked to answer with "Yes" or "No". The second question states: "On a scale from 0 to 10 , how much do you trust people in general, where 0 means «full distrust is better» and 10 means «full trust is better»?". The level of trust resulting from answers to these two questions should not depend on the subjects being attending a concert within the Festival "La Notte della Taranta". Rather, it should represent the individual's propensity to trust others due to his/her own beliefs and past experiences. Hence, we call it generalized trust, which is the individual rate of trust in others, irrespective of their identities, preferences or actions.

From the standpoint of "traditional" economic theory, based on the concept of the rational (and selfinterested) individual, trust has to be understood as an expensive act, because it puts the trusting person in a vulnerable position compared to other people. High trust individuals are more likely to be exposed, for example, to fraud and deception. "Rational" individuals are generally sucker averse: they attempt, in other words, to avoid being taken advantage of. ${ }^{20}$ In this sense, a high trust person can be defined as not sucker averse. Sabater-Grande and Georgantzìs (2002), in a series of laboratory experiments on the prisoner's dilemma, demonstrate that generally people with less monetary risk aversion show less sucker aversion. In other words, subjects who choose the action that is more likely to lead them to be deceived by others enjoy also risk in monetary choices. Many other studies,

\footnotetext{
${ }^{19}$ If he/she asks me to lend him/her money, because he/she was stolen his/her wallet during the concert, I easily do it. In addition, if I met him/her again one day and he/she is looking for a job that I am in a position to offer, I could prefer him/her to another person who, though having the same competences as him/her, did not share that personal, important experience with me long before.

${ }^{20}$ Burlando and Guala (2005) emphasize that sucker aversion is one of the possible motivations for "reciprocity" (be kind to those who are kind with me and unkind to those who are unkind with me). Hence, an individual should not necessarily be self-interested in order to show sucker aversion.
} 
crossing various disciplines, show that a person may take more trusting actions and/or actually trusts more when he/she is more willing to take a gamble (for example, within economics see Ben-Ner and Putterman, 2001 and the survey of Camerer, 2003; within philosophy, see Luhmann, 1979; within sociology, see Cook and Cooper, 2003). In our empirical enquiry, we therefore expect that individuals being very risk-averse in monetary choices produce little or no social capital at all. The opposite should be true for monetary risk-loving persons. The specific method we employed to assess risk aversion is widely used in economic literature (see, among others, Guiso and Paiella, 2008). Each interviewee was faced with a hypothetical situation: he or she was asked to choose whether to buy or not a ticket by contributing to create a fund, which would be randomly assigned to one out of 100 subjects (including the interviewee) who were attending the concert and would have bought the ticket as well. Since the degree of risk aversion varies with the price individuals are willing to pay in order to buy a lottery, knowing individuals' willingness to pay to participate in this risky lottery allows us to measure the degree of risk aversion. This hypothetical situation was proposed twice to each interviewee, with a high-price lottery, Lottery $H$, with price being $€ h$ (with $h$ being equal to either $5 €$ or $7 €$ ), and with a low-price lottery, Lottery $L$, which costs $€ l$ (with $l$ equal to either $0.5 €$ or $2 €){ }^{21}$

Thus, the measurement of social capital linked to the Festival consists of three main variables: the first one aims at determining the instantaneous trust in people attending the Festival, as a result of sharing a common experience; the second variable measures generalized trust in others and it is expected to be positively correlated with the instantaneous trust as defined above; the third variable should quantify instantaneous trust by translating it into less risk aversion. The last two measurements should serve as explanatory variables for instantaneous trust.

\subsection{Measurement Results}

Figure 2 shows that instantaneous social capital, measured as the proportion of the interviewees who positively answered the question on trust building out of all people answering it, ranges from a maximum of 4 spectators out of 10 and to a minimum of 2 participants out of 10 .

We note that instantaneous social capital is always higher in minor concerts than in the Final Concert. This seems to be at variance with those sociological theories (i.e., Le Bon, 2004) which see a positive correlation between the amount of social capital embedded in the act of sharing a value, a principle, an experience or a way of being and the origin of large popular movements and big changes in society. Under this perspective, when two or more people physically and/or mentally

\footnotetext{
${ }^{21}$ The order in which the two lotteries were presented to the interviewees has been inverted for half of them, so to control for order effects.
} 
meet and share something, as, for instance, an event full of tradition and identification like the one we analyze, the instantaneous social capital generated by that shared experience is expected to increase as the number of people attending the event rises. Our results show, however, the opposite. In our opinion, the explanation for this result is twofold.

Figure 2 - Instantaneous Social Capital: editions 2007-2011 of the Festival (minor concerts and Final Concert).

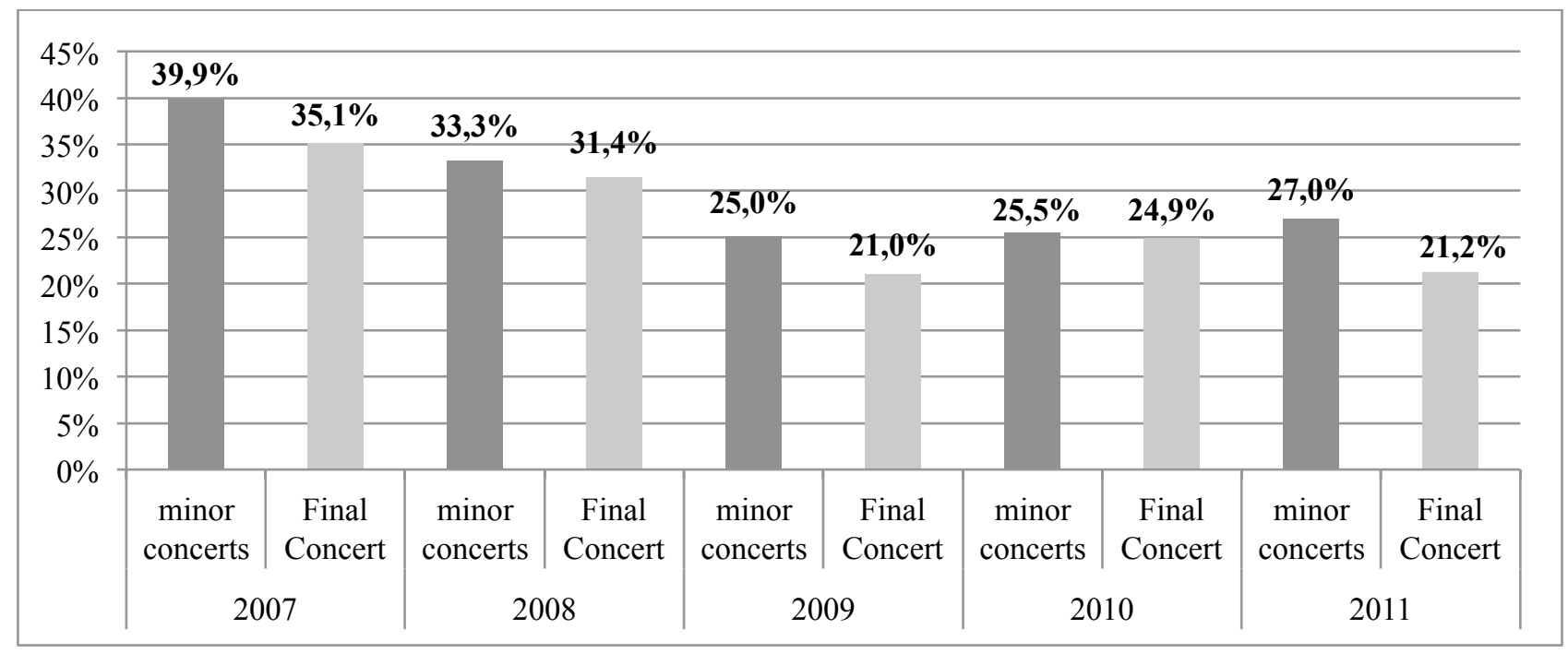

First of all, although the percentage of people who see the Final Concert as a cultural event is quite high ( $87 \%$ of the sample), the latter is mainly perceived as being an entertaining event and, therefore, attended and appreciated mostly by young people. On the contrary, the minor concerts are more frequently seen as being aimed at celebrating culture and traditions of the local area. ${ }^{22}$ This strongly affects the instantaneous social capital building. In minor concerts, indeed, the rate of instantaneous social capital building for those who state that they participate in the concert because of the traditions they represent is higher than for the rest of the sample (35\% and 30\%, respectively, significant at $1 \%$ level). In the Final Concert, those who declare that they attend the concert because of the crowded and entertaining atmosphere produce more instantaneous social capital (28\% vs $25 \%$ significant at $10 \%$ level). The difference in the amount of the generated instantaneous social capital between minor concerts' participants motivated by "traditions" and Final Concert's participants motivated by the "atmosphere" (35\% vs $28 \%$, significant at $1 \%$ level) confirms that the cultural motivation is more apt to stimulate the production of this kind of social capital.

Another explanation for the difference in instantaneous social capital generation between minor concerts and Final Concert could be provided as a criticism of sociological theories à la Le Bon

\footnotetext{
${ }^{22}$ Our data show that $28 \%$ of people attending minor concerts claim they participate in the event because of the traditions the event itself embodies; the corresponding percentage in the Final Concert lowers by almost 4 points. Also, participants in the Final Concert are more attracted by the opportunity of being together and amusing themselves with many people (33\% of the sample, $23 \%$ for minor concerts).
} 
(2004). Social capital production, instead of increasing with the number of subjects involved in the network which generates it, could rather follow a " $U$ " evolution. More precisely, instantaneous social capital could have a maximum effect when the interest group shrink to familism levels, decrease when this "family" expands and even disappear when the "family" dimension is no longer perceivable, reaching the midpoint, i.e. the lowest one, of the "U". According to this interpretation, each of the minor concerts of the Festival "La Notte della Taranta", on one side has a limited number of attendants (usually around 5.000) and on the other side preserves aspects of tradition, closeness, and familiarity typical of "village feasts". Thereby it conveys to the audience the feeling of being part of a small, recognizable group, in which the information gap on other members is minimal and mutual trust building is more immediate. This perception significantly drops in the crowded context of the Final Concert, with its 100.000 participants and its enormous dance floor. At the same time, however, if there were not 100.000 but, say, 1.000 .000 people attending the Final Concert, the instantaneous social capital generated could probably be similar or even higher than that one produced during minor concerts, because the sharing of the same experience could be perceived by participants as being "global", reaching, in the final part of the "U", the same level of social capital produced within a narrow family unit (first part of the "U").

Figure 2 presents another key result: instantaneous social capital, for both minor concerts and Final Concert, tends to decline over the first three years of the survey, though it slightly increases again through the two last editions $(2010,2011)$. Although it is not demonstrable through our available data, this effect is likely to depend on the economic crisis that, over the years of our survey, has severely affected the international economy and, above all, the relatively weak economy of Southern Italy and of the Province of Lecce as well. The economic-behavioral model underlying the explanation for this result is based on the following idea: by interpreting the generation of instantaneous social capital as the reduction of the information "gap" on other people (as stated above), we could state that the unfolding of the global economic crisis is likely to have widened this gap. Let us suppose, for instance, that before the crisis really started to show its effects on ordinary people in the summer of 2007 - a period when the levels of perceived wealth and perceived trustworthiness were still the highest - the generalized trust in others was on average high. Hence, the mere sharing of the experience of taking part in the Festival "La Notte della Taranta" would have been sufficient to make people perceive that additional amount of trust in all those who were attending the same concert, thus minimizing the information "gap" among them. Due to the spread of the international financial and economic crisis, the average generalized trust fell (or, equivalently, the gap widened). Hence, the additional amount of instantaneous trust generated during the participation 
in the event was not sufficient to reduce and/or bridge the information "gap" in order to allow people to trust a total stranger who was sharing their same experience.

The interrelation between generalized and instantaneous trust could be rather interpreted as a positive correlation between two indexes: the higher the individual's predisposition to trust others in general, the higher his/her willingness to "instantaneously" trust a "culturally close" person in a specific "context". The two questions about generalized trust introduced in the questionnaire proposed to participants in the last two editions (2010 and 2011) of the Festival aim at investigating this specific issue. We actually found a slight positive correlation (significant at $5 \%$ ) both between the generation of instantaneous trust linked to the participation in the event and the positive thinking that people are in general trustworthy $(0.14)$ and between the former and the fact of being in general a highly trusting person (0.21). The low correlation found between instantaneous and generalized trust though always positive and statistically significant - indirectly stresses the specific nature of instantaneous social capital, which does not necessarily need an individual predisposition to trust others in order to be activated.

A further analysis on the trend of instantaneous social capital according to interviewees' area of origin and residence is presented in Figure 3. Going back to the distinction among residents, native tourists and non-native tourists introduced at the end of section 2, we see that, in the first edition we analyzed, the average level of instantaneous social capital does not differ so much among these three categories. Since 2007, its trend is negative both for residents and for non-native tourists, with a more significant decrease for the former group of participants.

Figure 3 - Instantaneous Social Capital: ed. 2007-2011 of the Festival (residents, native tourists, non-native tourists).

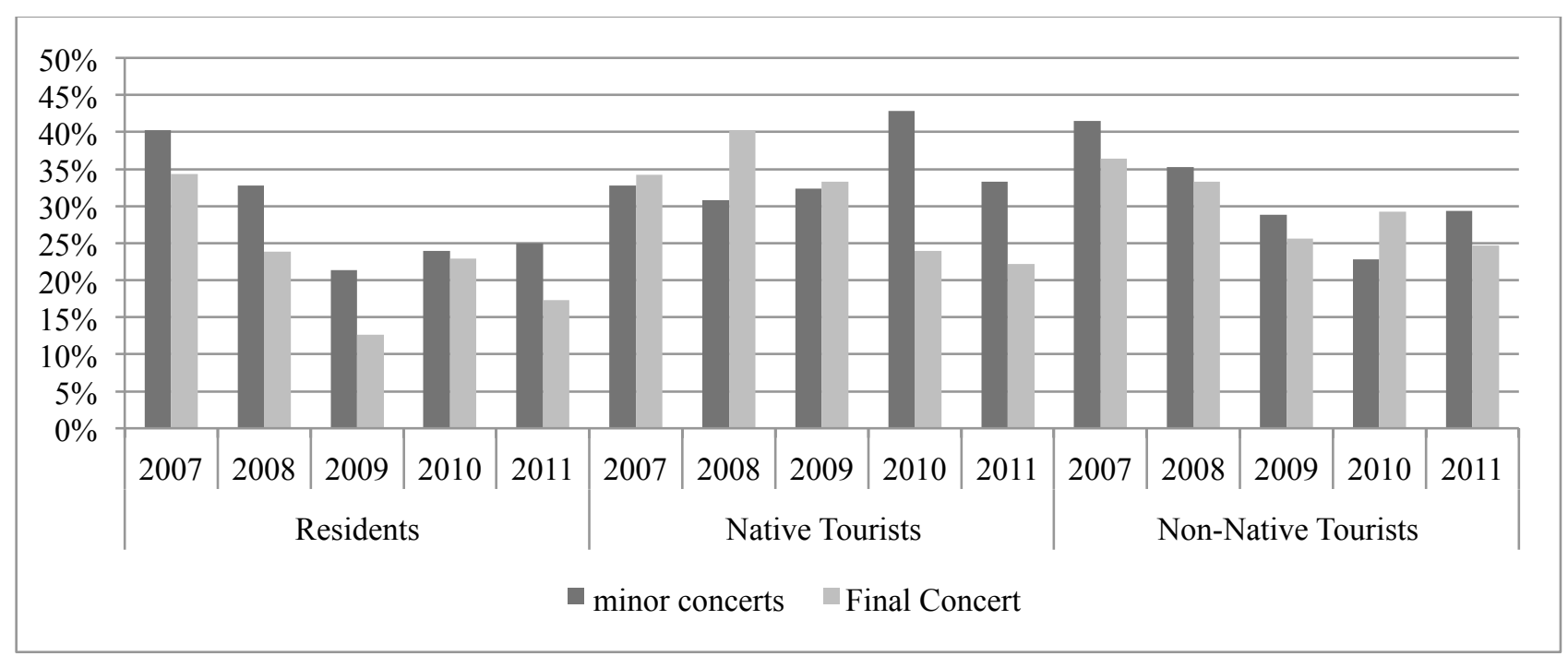

Apart from the possible effect of the economic crisis discussed above, the negative trend on residents can be partly explained by the fact that they may get "used" to the atmosphere of the Festival. In this 
sense, native tourists going to visit their home place during the summer do not show a negative trend in the level of instantaneous social capital over the editions 2007-2011 arguably because they "rediscover" every summer their tradition and culture, and thereby feel more their peculiarity. By attending the Festival once back in the Province of Lecce for their summer holidays, they are also looking for their origins and traditions. Those people are probably more likely to trust others when perceiving their own cultural environment - that they probably miss during the rest of the year - by participating in the event. This happens especially when the "protective" environment is represented by minor concerts (which are more familiar and intimate), rather than by the Final Concert.

Figure 3 indirectly shows another difference between instantaneous and generalized trust. As for the latter, Guiso et al. $(2004,2006)$ have demonstrated that individuals who live in a country different than their home country tend to "export" the home degree of trust to the place where they currently live. This does not happen for instantaneous social capital: the majority of non-native tourists attending the Festival come from Northern Italy, ${ }^{23}$ a region with a significantly higher level of generalized trust than Southern Italy. Despite that, native tourists produce the same level of instantaneous social capital as non-native tourists do on average over the five editions of the Festival (the difference in the instantaneous social capital produced by these two categories of tourists is not significant). Analyzing whether this is due more to the fact that native tourists reside during the year in the same area of non-native tourists (in this case, Northern Italy) or to the fact that instantaneous social capital is measured in the native tourists' home place is an interesting issue for further research.

Furthermore, by isolating within non-native tourists the group of greatly motivated, we see that they produce more instantaneous social capital than the rest of the sample (residents and tourists being motivated in part or not at all). This difference between greatly motivated tourists and the rest of the sampled population is more striking within the audience of minor concerts ( $44 \% \mathrm{vs} 31 \%$, significant at $1 \%$ ) than within the sample of participants in the Final Concert (32\% vs 25\%, significant at 1\%).

Let us now compare the level of instantaneous social capital produced by participants attending the Festival for the first time with that produced by "loyal consumers". Our data show that new participants produce on average more social capital than loyal Festival followers: this is true within the audience of both minor concerts $(34 \%$ vs $30 \%$, significant at $1 \%)$ and the Final event (29\% vs $23 \%$, significant at 1\%). Therefore, people attending the Festival "La Notte della Taranta" for the first time are more enthusiastic and willing to be involved in and get carried away by the event,

\footnotetext{
${ }^{23}$ Foreign non-native tourists (i.e., not Italian) represent a small percentage within the sample (around 5\% on average), both in minor concerts and in the Final Concert.
} 
feeling part of a group they probably had only heard about or that did not even know: "the Festival people".

As a greater amount of instantaneous trust is produced by neophytes, the term "instantaneous" could carry an additional meaning. This kind of trust is so fleeting, so closely related to that specific emotional moment, that it tends to decrease when people experience the festival attendance once again, i.e. when the sense of belonging to a selected group should be strengthened given the repetition of the same experience. One possible explanation might be that when "voluntarily" entering a new group, the early enthusiasm may lead one to think that other people in the group are trustworthy. Once the initial excitement dies down (and not because group experience is somehow negative, but due to a natural "customization" of the experience of participating in the Festival), trust in other group members decreases as well. This is because instantaneous trust does not depend on members' past behavior, but only on the very nature of the interest that binds the members of the group.

Our data show that the percentage of neophytes has fallen through the five years of the empirical research, especially within the audience of minor concerts (where they are usually less), but also among the participants in the Final Concert (where they are in general more). This provides an additional explanation for the decrease in the aggregate level of instantaneous social capital during the five editions 2007-2011 of the Festival.

So far, we have analyzed the main variables affecting the development of instantaneous social capital during the Festival and the reasons for its decline over the five-year period of the survey. However, in order to more precisely explain why there is a significant, constant difference over time between the average instantaneous social capital generated during minor concerts and the instantaneous trust produced by the audience of the Final Concert, we propose the following econometric analysis which links the level of instantaneous social capital found in the 2007-2011 Festival editions to some explanatory variables analyzed in all five years of our survey. Hence, we use a regression analysis in order to identify those participants' characteristics which contribute to the production of instantaneous social capital. In particular, our dependent variable is trust in other people attending the event (instantaneous social capital), while our explanatory variables are participants' age, education, monetary risk aversion and place of origin (residents, native tourists, non-native tourists). Furthermore, we added two binary variables for the data gathered across survey years 2008, 2009, 2010 and 2011 so as to control the downward trend observable in Figure 2. Finally, we put in the variable "positive mass gathering", whose value is equal to 1 if the interviewee thinks the term "mass meeting" has a positive meaning and to 0 otherwise. The other variables were constructed as follows. 
As far as the variable age is concerned, as we already did in the questionnaire, we partitioned the sample into five classes: under 25 (years old), between 26 and 30, between 31 and 39, between 40 and 60; over 60. Regarding gender, we use the standard partition: male vs. female. Education was determined by the last educational qualification acquired by the interviewee (primary school, secondary school, high school, university degree, post-graduate degrees). For the variable provenance, we used three binary variables, which take value 1 if the individual belongs to the reference category. Due to problems of collinearity, we excluded the binary variable "non-native tourists" from our regression. The monetary risk aversion comes from participants' willingness (less aversion) or unwillingness (greater aversion) to buy the lottery presented in the two hypothetical questions in the questionnaire. As explained in the previous paragraph, we separated two variables indicating the lottery: the lottery with a higher purchase price (lottery $H$ ) and the lottery with a lower purchase price (lottery $L$ ).

Since our dependent variable is a binary variable, we used a probit regression model. The results of this analysis are reported in Table 6. Coefficients refer to the marginal effects of the explanatory variables on instantaneous social capital. In the regressions, we also included some binary variables, which are used to control the order of hypothetical questions on lotteries and their different purchase prices.

Table 6 - Probit Regression, Instantaneous Social Capital.

\begin{tabular}{|c|c|c|c|c|c|c|}
\hline & \multicolumn{4}{|c|}{ Separate Regressions } & \multicolumn{2}{|c|}{ Joint Regression } \\
\hline & \multicolumn{2}{|l|}{ minor concerts } & \multicolumn{2}{|l|}{ Final Concert } & & \\
\hline Lottery $H$ & 0,0695 & $* * *$ & 0,0540 & $* * *$ & 0,0645 & $* * *$ \\
\hline Lottery L & 0,0888 & $* * *$ & 0,1236 & $* * *$ & 0,1009 & $* * *$ \\
\hline Greatly motivated & 0,0726 & $*$ & 0,0390 & & 0,0539 & $* *$ \\
\hline In part motivated & 0,0564 & $* *$ & 0,0743 & $* * *$ & 0,0676 & $* * *$ \\
\hline Mass Gathering perceived as positive & 0,0550 & $* * *$ & 0,0709 & $* * *$ & 0,0610 & $* * *$ \\
\hline Residents & $-0,0529$ & $* *$ & $-0,0479$ & $*$ & $-0,0490$ & $* * *$ \\
\hline Non-Native Tourists & $-0,0230$ & & $-0,0006$ & & $-0,0103$ & \\
\hline Education & $-0,0283$ & $* *$ & $-0,0478$ & $* * *$ & $-0,0374$ & $* * *$ \\
\hline Age & 0,0098 & & 0,0032 & & 0,0077 & \\
\hline $\operatorname{Sex}$ & $-0,0037$ & & $-0,0207$ & & $-0,0078$ & \\
\hline Year 2008 & $-0,1221$ & & $-0,0316$ & & $-0,0804$ & $* *$ \\
\hline Year 2009 & $-0,1985$ & $* *$ & $-0,1222$ & $* * *$ & $-0,1743$ & $* * *$ \\
\hline Year 2010 & $-0,1490$ & $* * *$ & $-0,0885$ & $* *$ & $-0,1229$ & $* * *$ \\
\hline Year 2011 & $-0,1661$ & $* *$ & $-0,2134$ & $* * *$ & $-0,2175$ & $* * *$ \\
\hline Concertone (dummy) & - & & - & & $-0,0584$ & $* * *$ \\
\hline \multicolumn{7}{|l|}{$* * *=$ Significant at $1 \%$} \\
\hline $\begin{array}{l}* *=\text { Significant at } 5 \% \\
* \quad=\text { Significant at } 10 \%\end{array}$ & & & & & & \\
\hline
\end{tabular}


First of all, we note that there are no significant gender and age effects: for both variables the regression coefficient is very close to zero, which implies that these two variables are not relevant for instantaneous social capital. This is a somewhat surprising result with regard to age, as young people (under 25 years old) are supposed to produce in principle more instantaneous social capital, and given the heterogeneity of the distribution of this variable across minor concerts and Final Concert. People aged under 25 seem to be stimulated in the development of instantaneous social capital by all Festival concerts (about 30\% out of the participants in both minor concerts and Final Concert positively answered the question on instantaneous social capital). As age increases, instantaneous social capital goes down (but not significantly) for the Final Concert and it goes up (but not significantly) for minor concerts. Within the category "aged between 26 and 30", only $24 \%$ out of the interviewees answered positively the question during the Final Concert, compared to $33 \%$ during minor concerts. "Over 60" participants make the level of instantaneous social capital further go down within the sample of the Final Concert (19\%), while "over 60 " participants in minor concerts produced the same level of instantaneous social capital as "under 25 " young people.

On the contrary, the educational attainment negatively and significantly affects instantaneous social capital: less educated people seem to produce more instantaneous social capital. The marginal effect is slightly larger in the Final Concert.

Moreover, participants who reside in the place where the concert takes place or in the Province of Lecce have a negative impact on instantaneous social capital, meaning that being resident in the area where the Festival is held reduces the probability of generating trust and, consequently, social capital. Hence, social capital building seems to be related to the tourist status. In particular, native tourists are those who produce more social capital, both in minor concerts and in the Final Concert, even though this positive effect is not statistically significant. Being on holidays in the Province of Lecce just or also because of the Festival has a positive impact on instantaneous social capital creation.

Further, whether a mass gathering is considered as something positive or not positively affects the instantaneous social capital building, an effect that is mainly detected for the Final Concert. Our data show that there are many participants (79\%) declaring that the concerts of the Festival are mass meetings. Arguably, participants who interpret the expression "mass gathering" in its negative sense at the same time thinking that the Festival belongs to this category fail to perceive its intrinsic cultural value, thereby ignoring the feeling of sharing a unique experience with other participants. Lastly, monetary risk aversion plays a significant role in the social capital creation. As pointed out in the previous paragraph, a negative relation between risk aversion and instantaneous social capital is normally expected to be found. In our case, both variables "lottery $H$ " and "lottery $L$ " take value 1 
when the lottery is bought and value 0 otherwise. The individual's degree of monetary risk aversion is minimum when both variables take value 0 . In particular, the agent who chooses to buy the (lowprice and also the) high-price lottery is less (monetary) risk averse than the agent who chooses to buy only the low-price lottery. From this perspective, the two variables have the expected sign (Table 6): the lower the monetary risk aversion (or, the higher the monetary risk propensity), the higher the level of instantaneous social capital produced.

As Table 6 shows, the marginal effect of the variable "lottery $H$ " is higher than the marginal effect of the variable "lottery $L$ ". Also, the latter, although positive, is lower for the Final Concert than for minor concerts, ceteris paribus: this suggests that the degree of risk propensity needed to build social capital is higher during the Final Concert, due to the fact that it is perceived on average as a more risky event in terms of trust. Nevertheless, those who are risk seeking enough to buy the high-price lottery produce more instantaneous social capital during the Final Concert. This in part relates to the different size of the events. Indeed, it is possible that, by construction, the lotteries lead subjects to perceive the probability of winning as being higher in minor concerts than in the Final Concert, given the larger number of participants in the latter.

Hence, a lottery with the same price and the same number of people taking part in it might have been regarded as being more risky when proposed during the Final Concert rather than during minor concerts, making people attending minor concerts more willing to buy it. As a matter of fact, $31 \%$ of the participants in the Final Concert choose to buy the lottery $L$ and only $16 \%$ buy the lottery $H$; the corresponding percentages for minor concerts are $39 \%$ and $19 \%$.

The reason why buying lottery $H$ generates more instantaneous social capital during the Final Concert strongly depends on the small number of people who decide to buy that lottery. By construction, if the number of subjects with a certain characteristic (in our case, "trusting people") is very large, then the marginal effect resulting from adding one more subject is almost nonexistent; if the group of subjects is narrow enough, on the contrary, the marginal effect deriving from adding one more subject to the group is very large. This still does not explain why the same mechanism does not apply to lottery $L$. Since the probability of winning this lottery is lower in the Final Concert than in minor concerts anyway, we expect fewer participants in the Final Concert to buy that lottery and the resulting impact on social capital to be positive (given the small number of people who buy the lottery). The data we collected, though, do not confirm our expectations. Our explanation is that there might be a second order effect related to the total amount of money that may be collected in case of a win. When presented with the high-price lottery $H$, the interviewees mind more the probability of winning than the potential gains in case of a win, so they buy it more frequently during minor concerts than during the Final Concert, where the probability of winning is lower. When faced with 
the low-price lottery $L$, instead, interviewed subjects pay more attention to the potential amount of money they can win than to the probability of winning. This explains why lottery $L$ is bought "quite frequently" in the Final Concert as well, where by "quite frequently" we mean that also those who are very risk averse buy lottery $L$ during the Final Concert, and "mingle" with risk loving subjects, so to lessen the effect of lottery $L$ on instantaneous social capital.

We conclude this section by analyzing the potential relations between the level of instantaneous social capital obtained in the 2007-2011 Festival editions and the short-term economic impact of the Festival as measured in section 3.

Given the limited sample size, it is not possible to use a proper statistical methodology for the aggregate data. Therefore, it is worth relying on a visual chart. Figure 4 displays the relation between the average level of instantaneous social capital and the overall economic impact of the Festival, for both greatly motivated tourists only and greatly and in part motivated tourists together. The overall economic impact has been calculated at the end of section 3, as the sum of aggregate values in Table 3 and in Table 5 .

Figure 4 - Relation between average instantaneous social capital and aggregate economic impact, by subgroups of tourists.

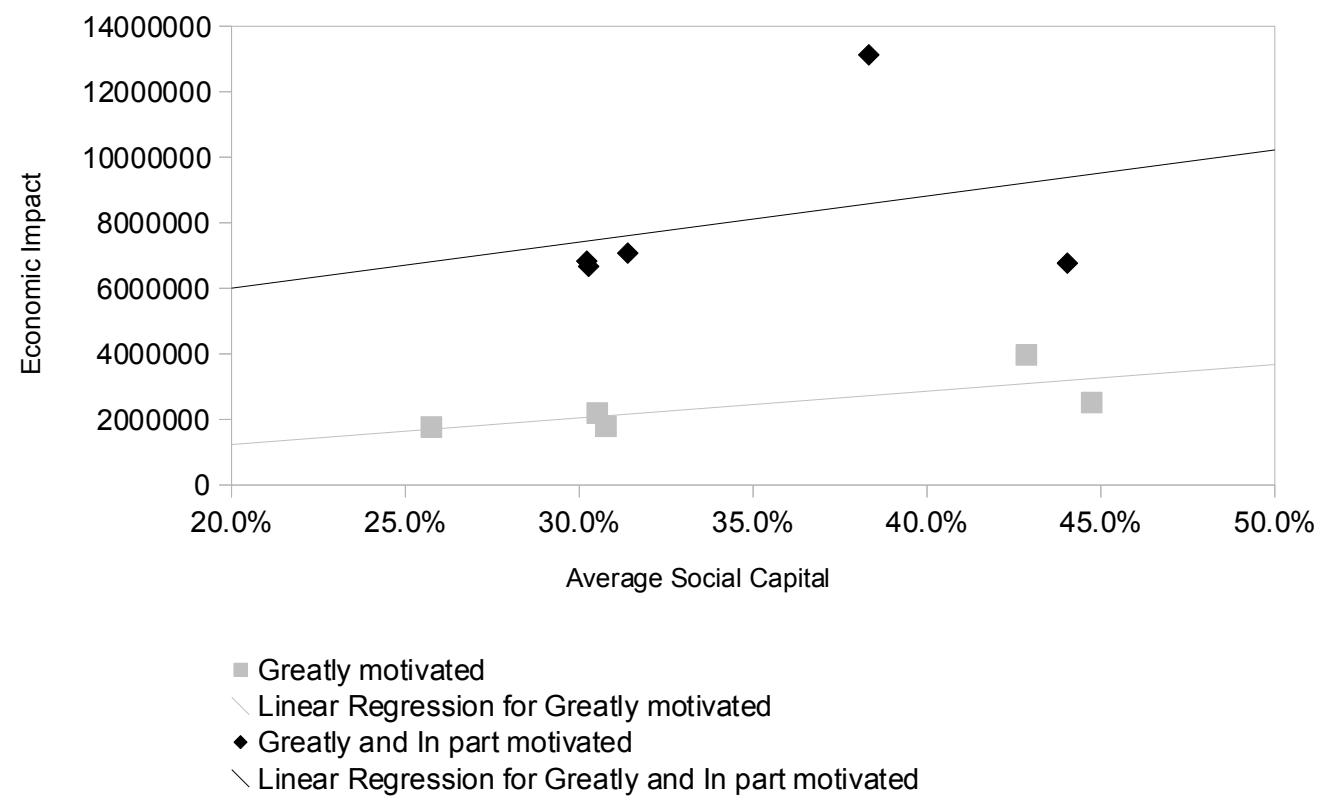

From the dispersion of the data points on the chart, we can see that there is a steadily increasing relation between average instantaneous social capital and overall economic impact for the subcategory of greatly motivated tourists only (grey squares). When the two sub-categories are merged 
(black diamonds), although the slope of the line is still positive, there is too much dispersion of the data to give solid conclusions.

In order to give more solid bases to our aggregate findings, we explore data at the micro level. We can, in fact, test if the sub-group of greatly and in part motivated tourists with positive social capital spends, on average, more than the sub-group of tourists with no social capital. For the sake of clarity, we refer to the former sub-group as sub-group 1, and to the latter as sub-group 0 . We use both parametric (unpaired T-test) and non-parametric (rank sum) testing.

If in the first sub-category we include only greatly motivated tourists, the parametric test gives a statistically significant difference between the two sub-categories at $10 \%$ for the two-tailed hypothesis (i.e., average spending of sub-group 1 = average spending of sub-group 0 ); and at $5 \%$ for the one-tailed hypothesis (i.e., average spending of sub-group $1>$ average spending of sub-group 0 ). The non-parametric test delivers similar conclusions as the rank of sub-group 1 is higher than the rank of subgroup 0 (with $10 \%$ level of significance). Conversely, if in the first sub-category we include both greatly and in part motivated tourists, we do not find any significant difference between the two sub-categories according to any of the two tests used. This result confirms our aggregate findings.

\section{Conclusion}

In this paper we have introduced and analyzed the concept of instantaneous social capital (i.e. deriving from the mere participation to a unique cultural event) and studied the short-term effects of this event in terms of local economic development.

By means of a 5-year field study of the socio-economic impact of the most important European music festival dedicated to traditional music, we have shown the importance of culture in terms of both touristic attraction and creation of instantaneous social ties. These ties make both residents and tourists participating in the cultural event believe that they belong to the same virtual community, thereby increasing the level of trust among participants who actually do not know each other.

The cultural event being the object of our case study is the Festival "La Notte della Taranta" (about 170.000 participants per year since 2007), an itinerant festival of around 15 concerts of traditional popular music performed over a span of 2-3 weeks in August each year since 1998. This festival, although organized in an area historically poor both in terms of economic resources and social capital, has been able to dramatically stimulate the local economy through the rediscovery and promotion of local cultural heritage and by placing it in contact with the outside. 
Our evidence is based on a large survey, consisting of nearly 10.000 interviews to Festival participants over a span of five editions (2007-2011). The questionnaire proposed to the Festival participants has been structured to assess the socio-economic impact of the event on the region where it is held and its sociological effects on people attending the concerts.

The contribution of the paper is twofold.

First of all, we provide an estimate of the local economic agents' short-term (direct and indirect) revenues coming from tourists attracted by an itinerant cultural event. More specifically, we calculated the short-term shock of demand generated by the Festival "La Notte della Taranta" on specific sectors of the economy of southern Italian area where it is held: accommodation, food, bar \& pubs, and local transportation. We acknowledge that it is quite restrictive to study the economic impact produced by an event by only focusing on the period during which it takes place. However, the short-term impact on the local economy has its own intrinsic value: it represents the lower bound of the overall economic impact that the event generates. A careful analysis of our survey data shows that, against a total cost slightly greater than 4.5M€ over the editions 2007-2011, the Festival "La Notte della Taranta" produced in the corresponding five months of August a total economic impact due to touristic attraction amounting to at least $15 \mathrm{M} €$. In particular, the return on investment analysis shows that the initial investment has brought a short-term return worth more than two times as much. Furthermore, we analyze the time effects of an increase in the cultural investment in a specific edition of the Festival. We find that the positive shock resulting from the large investment has a strong positive impact on the short-run revenues in the following edition, with this positive effect rapidly disappearing in the subsequent editions at an aggregate level. Our analysis of the economic impact of the Festival relies on two main explanatory variables. Indeed, we distinguish between nonnative tourists on holidays in the area just because of the Festival (greatly motivated) and those who are there also because of the Festival (in part motivated). Also, we disentangle the economic effects of the two sub-events that constitute the itinerant festival under analysis: the initial series of minor concerts - which more closely represent the local cultural heritage - and the Final Concert, which, with its 100.000 participants, is mainly attended for its mass gathering dimension.

The second contribution of the paper consists in the investigation of the impact of a cultural event on the community of its participants, in terms of social capital and trust building. Our field study aimed therefore at extracting a form of trust that is generated by the mere fact of taking part in a shared experience and that could soon evaporate once this experience ends. In this sense, it would be "instantaneous" both in its formation and in its expiration. Arguably, such kind of trust rests upon the fact that people feel they know other people within the audience better by realizing they have similar tastes given that they are sharing the same "cultural" experience. 
Our research shows that both gender and age have no effect on the creation of instantaneous social capital. On the contrary, educational attainments negatively and significantly affect instantaneous social capital, with less educated people being more inclined to trust other people because of the common participation in the same cultural event. Being resident in the area where the Festival is held reduces the probability of generating trust and, consequently, social capital, while native tourists are those who produce more social capital (this positive effect is not statistically significant though). Moreover, being on holidays in the area where the Festival is held just or also because of the Festival has a positive impact on social capital creation. Furthermore, whether a mass gathering is considered as something positive or not positively affects the social capital building. Participants who interpret the expression "mass gathering" in its negative sense and think, at the same time, that the Festival belongs to this category fail to perceive its intrinsic cultural value, thereby ignoring the feeling of sharing a unique experience with other participants. Finally, we find that a lower monetary risk aversion leads to a higher level of instantaneous social capital.

The insights from our case study and the related analysis in the paper have interesting policy implications. We claim that financing and organizing cultural events linked to history and traditions of a community can lead to the overall socio-economic development of this community, due not only to the direct and induced economic impact that the tourist flow produces in the short-term. Culture positively affects the behavior of those people who directly - through participation - and indirectly through the strengthening of cultural identity - benefit from the event. Our analysis demonstrates that these effects could soon evaporate where the event ends, thus not leading to the creation of generalized trust. Therefore, the production of a successful gathering event itself is not a long-term economic development. Local public institutions should acknowledge this point, thereby promoting the accumulation of (instantaneous) social capital generated by the event through cultural policies designed to make benefits persistent and long lasting, likely to produce temporally and spatially widespread economic effects. Furthermore, regions that are poor in their endowment of economic resources and social capital could find in cultural investment an innovative strategy to get out from their backwardness. This could stimulate the creation of new bonds between the local economy and the outside, through cultural tourism. This paper shows how these bonds may be virtuous, especially when the region where the cultural event is held happens to be perceived as a cradle of long-lasting and deep-rooted traditions. 


\section{References}

Alesina A., La Ferrara E. (2002), Who trusts others?, Journal of Public Economics, 85, 207-234.

Arcodia C., Whitford M. (2006), Festival attendance and the development of social capital, Journal of Convention \& Event Tourism, 8, 1-18.

Attanasi F. M. (2007), La musica nel tarantismo. Le fonti storiche, edizioni ETS, Pisa.

Ben-Ner A., Putterman L. (2001), Trusting and trustworthiness, Boston University Law Review, 81, 523-551.

Bowles S., Gintis H. (2002), Social capital and community governance, Economic Journal, 112, F419-F436.

Burlando R., Guala F. (2005), Heterogeneous agents in public goods experiments, Experimental Economics, 8, 35-54.

Butler J., Giuliano P., Guiso L. (2009), The right amount of trust, NBER Working Papers 15344.

Camerer C. F. (2003), Behavioral game theory, Princeton University Press/Russell Sage Foundation, Princeton/New York.

Cook K. S., Cooper R.M. (2003), Experimental studies of cooperation, trust, and social exchange, in Ostrom E., Walker J. (eds.), Trust and reciprocity, Russell Sage, New York, 209-244.

David Q., Janiak A., Wasmer E. (2010), Local social capital and geographical mobility, Journal of Urban Economics, 68, 191-204.

Durlauf S. (2002), On the empirics of social capital, Economic Journal, 112, F459-F479.

Earls Z. (1993), First night celebration: building community through the arts, Festival and Event Tourism, 1, 32-33.

Falassi A. (1987), Festival: definition and morphology, in A. Falassi (Ed.), Time out of time, University of New Mexico Press, Albuquerque, NM.

Fukuyama F. (1996), Trust: the social virtues and the creation of prosperity, Simon \& Schuster, New York.

Fukuyama F. (1999), The great disruption, Simon \& Schuster, New York.

Getz D. (1997), Event management and event tourism, Cognizant, New York.

Girard F. L. (2008), Cultural tourism: from culture fruition to culture communication and production, International Journal Services Technology and Management, 10, 15-28.

Guiso L., Paiella M. (2008), Risk aversion, wealth and background risk, Journal of the European Economics Association, 6, 1109-1150.

Guiso L., Sapienza P., Zingales L. (2003), People's opium? Religion and economic attitudes, Journal of Monetary Economics, 50, 225-282.

Guiso L., Sapienza P., Zingales L. (2004), Cultural biases in economic exchange, NBER Working Papers 11005.

Guiso L., Sapienza P., Zingales L. (2006), Does culture affect economic outcomes?, NBER Working Papers 11999.

Guiso L., Sapienza P., Zingales L. (2008a), Social capital as good culture, Journal of the European Economic Association, 6, 295-320.

Guiso L., Sapienza P., Zingales L. (2008b), Trusting the stock market, Journal of Finance, 63, 25572600.

Kan K. (2007), Residential mobility and social capital, Journal of Urban Economics, 61, 436-457.

Kolb B. M. (2005), Marketing for cultural organisations. New strategies for attracting audiences to classical music, dance, museums, theatre and opera, Thomson Learning, London.

Le Bon G. (2004), Psicologia delle folle, Saggistica TEA, Milano.

Leontief W. W. (1986), Input-Output economics, Oxford University Press, New York.

Luhmann N. (1979), Trust: a mechanism for the reduction of social complexity, in Luhmann N. (ed.), Trust and power, Wiley, New York, 4-103.

Macbeth J. (1997), Tourism and the district of Omeo. Final report of the Omeo District Sustainable Community Project, Murdoch University, Perth. 
Macbeth J., Carson D., Northcote J. (2004), Social capital, tourism and regional development: SPCC as a basis for innovation and sustainability, Current Issues in Tourism, 7, 502-522.

Marbach G. (2000), Le ricerche di mercato, Utet, Torino.

Portes A. (1998), Social capital: its origins and application in modern sociology, Annual Review of Sociology, 24, 1-24.

Putnam R. D. (2000), Bowling alone. The collapse and revival of American community, Simon \& Schuster, New York.

Russell J. F. (1979), Tarantism, Medical History, 23, 404-425.

Sabater-Grande G., Georgantzìs N. (2002), Accounting for risk aversion in repeated prisoners' dilemma games: an experimental test, Journal of Economic Behavior and Organization, 48, 37-50.

Salamone F. (2000), Society, culture, leisure and play: an anthropological reference, University Press of America, Maryland.

Schuster J. (1995), Two urban festivals: La Merce and First Night, Planning Practice and Research, 10, 173-187.

Sheldon P. J. (1990), A review of tourism expenditure research, in C.P. Cooper (ed.), Progress in tourism, recreation and hospitality management, vol. 2, Belhaven Press, London, 28-49.

Stäglin R. (1972), MODOP - Ein Verfahren zur Erstellung empirischer Transaktionsmatrizen. Anwendung statistischer und mathematischer Methoden auf sozialwissenschaftliche Probleme, Arbeiten zur Angewandten Statistik, 15, 69-81.

Stäglin R. (1973), Methodische und rechnerische Grundlagen der Input-Output-Analyse, in R. Krengel (hrsg.), Aufstellung und Analyse von Input-Output-Tabellen, Vandenhoeck and Ruprecht, Göttingen, 27-54.

Stynes D. J., Propst D. B., Wen-Huei C., YaYen S. (2000), Estimating National Park visitor spending and economic impacts: the MGM2 model, Working Paper Michigan State University.

Yeoman I., Robertson M., Ali-Knigt J., Drummond S., McMahon-Beattie U. (eds) (2004), Festival and events management: an international arts and culture perspective, Elsevier, Oxford. 


\section{Appendix}

Table A.1 - Estimated number of Residents, Native Tourists and Non-native Tourists (and, among those, greatly and in part motivated) in the audience of the Festival "La Notte della Taranta" (editions 2007-2011).

\begin{tabular}{|c|c|}
\hline \multicolumn{2}{|l|}{2007} \\
\hline minor concerts & 68.000 \\
\hline Residents & 28.000 \\
\hline Native Tourists & 8.800 \\
\hline Non-native Tourists (NnT) & 31.200 \\
\hline NnT: Greatly motivated & 5.100 \\
\hline NnT: In part motivated & 12.500 \\
\hline \multicolumn{2}{|l|}{2008} \\
\hline minor concerts & 71.500 \\
\hline Residents & 28.000 \\
\hline Native Tourists & 9.800 \\
\hline Non-native Tourists (NnT) & 33.700 \\
\hline NnT: Greatly motivated & 5.300 \\
\hline NnT: In part motivated & 14.800 \\
\hline \multicolumn{2}{|l|}{2009} \\
\hline minor concerts & 65.000 \\
\hline Residents & 37.000 \\
\hline Native Tourists & 5.500 \\
\hline Non-native Tourists (NnT) & 22.500 \\
\hline NnT: Greatly motivated & 1.400 \\
\hline NnT: In part motivated & 8.600 \\
\hline \multicolumn{2}{|l|}{2010} \\
\hline minor concerts & 60.000 \\
\hline Residents & 36.000 \\
\hline Native Tourists & 2.900 \\
\hline Non-native Tourists (NnT) & 21.100 \\
\hline NnT: Greatly motivated & 2.800 \\
\hline NnT: In part motivated & 9.100 \\
\hline \multicolumn{2}{|l|}{2011} \\
\hline minor concerts & 85.000 \\
\hline Residents & 47.000 \\
\hline Native Tourists & 6.500 \\
\hline Non-native Tourists (NnT) & 31.500 \\
\hline NnT: Greatly motivated & 3.800 \\
\hline NnT: In part motivated & 13.100 \\
\hline
\end{tabular}

\begin{tabular}{|c|c|}
\hline \multicolumn{2}{|l|}{2007} \\
\hline Final Concert & 100.000 \\
\hline Residents & 32.500 \\
\hline Native Tourists & 17.800 \\
\hline Non-native Tourists (NnT) & 49.700 \\
\hline NnT: Greatly motivated & 21.800 \\
\hline NnT: In part motivated & 16.200 \\
\hline \multicolumn{2}{|l|}{2008} \\
\hline Final Concert & 150.000 \\
\hline Residents & 48.000 \\
\hline Native Tourists & 31.000 \\
\hline Non-native Tourists (NnT) & 71.000 \\
\hline NnT: Greatly motivated & 18.800 \\
\hline NnT: In part motivated & 28.500 \\
\hline \multicolumn{2}{|l|}{2009} \\
\hline Final Concert & 100.000 \\
\hline Residents & 37.500 \\
\hline Native Tourists & 9.000 \\
\hline Non-native Tourists (NnT) & 53.500 \\
\hline NnT: Greatly motivated & 15.800 \\
\hline NnT: In part motivated & 20.000 \\
\hline \multicolumn{2}{|l|}{2010} \\
\hline Final Concert & 100.000 \\
\hline Residents & 45.500 \\
\hline Native Tourists & 5.100 \\
\hline Non-native Tourists (NnT) & 49.400 \\
\hline NnT: Greatly motivated & 18.400 \\
\hline NnT: In part motivated & 20.500 \\
\hline \multicolumn{2}{|l|}{2011} \\
\hline Final Concert & 90.000 \\
\hline Residents & 37.200 \\
\hline Native Tourists & 7.800 \\
\hline Non-native Tourists (NnT) & 45.000 \\
\hline NnT: Greatly motivated & 15.500 \\
\hline NnT: In part motivated & 18.000 \\
\hline
\end{tabular}


Table A.2 - Demand multipliers by sector (Italy vs Province of Lecce).

\begin{tabular}{|l|c|c|}
\hline \multicolumn{1}{|c|}{ Sector } & $\begin{array}{c}\text { Multipliers } \\
\text { Italy }\end{array}$ & $\begin{array}{c}\text { Multipliers } \\
\text { Lecce }\end{array}$ \\
\hline A: Agriculture, Forestry and Fishing & 1,62 & 1,55 \\
\hline B: Mining and Quarrying & 1,14 & 1,08 \\
\hline C: Manufacturing & 2,12 & 1,46 \\
\hline D: Electricity, gas \& water supply & 1,94 & 1,17 \\
\hline E: Construction & 2,15 & 1,90 \\
\hline F: Retail and wholesale trade & 2,03 & 1,80 \\
\hline G: Transportation and warehousing & 2,04 & 1,82 \\
\hline H: Restaurants \& hotels & 1,96 & 1,32 \\
\hline I: IT \& Communication Services & 1,84 & 1,29 \\
\hline L: Finance \& insurance & 1,69 & 1,38 \\
\hline M: Real estate & 1,20 & 1,14 \\
\hline N: Scientific \& professional activities & 1,79 & 1,51 \\
\hline O: Travel and rental agencies & 2,14 & 1,71 \\
\hline P: Education & 1,19 & 1,16 \\
\hline Q: Social and health care & 1,53 & 1,40 \\
\hline R: Leisure & 1,86 & 1,22 \\
\hline S: Other services & 1,66 & 1,33 \\
\hline
\end{tabular}

Table A.3 - Distribution of length of stay (Short, Medium or Long) of greatly motivated and in part motivated tourists.

\begin{tabular}{|c|c|c|c|c|c|c|c|c|c|c|c|c|}
\hline & \multicolumn{6}{|c|}{ minor concerts } & \multicolumn{6}{|c|}{ Final Concert } \\
\hline & \multicolumn{3}{|c|}{ Greatly motivated } & \multicolumn{3}{|c|}{ In part motivated } & \multicolumn{3}{|c|}{ Greatly motivated } & \multicolumn{3}{|c|}{ In part motivated } \\
\hline & $\begin{array}{c}\% \text { of } \\
S\end{array}$ & $\begin{array}{c}\% \text { of } \\
M\end{array}$ & $\begin{array}{c}\% \text { of } \\
L\end{array}$ & $\begin{array}{c}\% \text { of } \\
S\end{array}$ & $\begin{array}{c}\% \text { of } \\
M\end{array}$ & $\begin{array}{c}\% \text { of } \\
L\end{array}$ & $\begin{array}{c}\% \text { of } \\
S\end{array}$ & $\begin{array}{c}\% \text { of } \\
M\end{array}$ & $\begin{array}{c}\% \text { of } \\
L\end{array}$ & $\begin{array}{c}\% \text { of } \\
S\end{array}$ & $\begin{array}{c}\% \text { of } \\
M\end{array}$ & $\begin{array}{c}\% \text { of } \\
L\end{array}$ \\
\hline 2007 & 17.7 & 47.9 & 34.4 & 5.4 & 31.0 & 63.6 & 78.8 & 9.9 & 11.3 & 15.0 & 29.9 & 55.1 \\
\hline 2008 & 13.3 & 60.0 & 26.7 & 9.3 & 37.2 & 53.5 & 69.7 & 9.1 & 21.2 & 15.1 & 37.0 & 47.9 \\
\hline 2009 & 16.7 & 29.2 & 54.1 & 10.5 & 41.5 & 48.0 & 75.8 & 15.2 & 9.0 & 17.8 & 41.7 & 40.5 \\
\hline 2010 & 25.0 & 50.0 & 25.0 & 7.8 & 45.1 & 47.1 & 80.2 & 13.4 & 6.4 & 25.3 & 46.1 & 28.6 \\
\hline 2011 & 30.3 & 39.4 & 30.3 & 7.5 & 67.5 & 25.0 & 90.2 & 4.1 & 5.7 & 32.5 & 47.5 & 20.0 \\
\hline
\end{tabular}


Table A.4 - Average daily expenses (in €) of greatly motivated and in part motivated tourists.

\begin{tabular}{|l|c|c|c|c|}
\cline { 2 - 5 } \multicolumn{1}{c|}{} & \multicolumn{2}{c|}{ minor concerts } & \multicolumn{2}{c|}{ Final Concert } \\
\hline $\begin{array}{l}\text { Festival } \\
\text { Editions }\end{array}$ & $\begin{array}{c}\text { Greatly } \\
\text { motivated }\end{array}$ & $\begin{array}{c}\text { In part } \\
\text { motivated }\end{array}$ & $\begin{array}{c}\text { Greatly } \\
\text { motivated }\end{array}$ & $\begin{array}{c}\text { In part } \\
\text { motivated }\end{array}$ \\
\hline 2007 & 39.4 & 40.5 & 35.7 & 24.7 \\
\hline 2008 & 63.5 & 67.2 & 44.6 & 41.2 \\
\hline 2009 & 57.9 & 60.0 & 36.0 & 36.9 \\
\hline 2010 & 69.0 & 68.9 & 42.7 & 46.2 \\
\hline 2011 & 46.2 & 51.2 & 35.8 & 53.3 \\
\hline
\end{tabular}

Table A.5 - Average daily expenses (in $€$ ) of greatly motivated and in part motivated tourists per services bought and length of stay (Short, Medium or Long).

\begin{tabular}{|c|c|c|c|c|c|c|}
\hline & \multicolumn{3}{|c|}{ Greatly motivated } & \multicolumn{3}{|c|}{ In part motivated } \\
\hline & $S$ & $M$ & $L$ & $S$ & $M$ & $L$ \\
\hline \multicolumn{7}{|l|}{ minor concerts } \\
\hline Accomodation & 20.0 & 19.6 & 21.7 & 18.5 & 20.4 & 19.4 \\
\hline Food & 21.2 & 17.5 & 18.5 & 17.2 & 16.8 & 18.2 \\
\hline Bar \& Pubs & 5.9 & 6.1 & 6.4 & 8.8 & 8.1 & 9.7 \\
\hline Trasportation & 11.9 & 11.2 & 13.1 & 12.9 & 11.5 & 12.2 \\
\hline \multicolumn{7}{|l|}{ Final Concert } \\
\hline Accomodation & 13.1 & 12.5 & 18.0 & 12.2 & 13.6 & 11.4 \\
\hline Food & 15.9 & 11.8 & 16.6 & 11.8 & 12.0 & 12.0 \\
\hline Bar \& Pubs & 5.4 & 7.3 & 7.1 & 8.9 & 8.0 & 10.5 \\
\hline Trasportation & 6.9 & 7.8 & 10.3 & 9.1 & 7.4 & 8.9 \\
\hline
\end{tabular}

Table A.6 - Probability of participating to more than one concert given length of stay (Short, Medium or Long) of greatly motivated and in part motivated tourists.

\begin{tabular}{|c|c|c|c|c|c|c|}
\hline & \multicolumn{3}{|c|}{ Greatly motivated } & \multicolumn{3}{|c|}{ In part motivated } \\
\hline & $S$ & $M$ & $L$ & $S$ & $M$ & $L$ \\
\hline \multicolumn{7}{|c|}{ minor concerts } \\
\hline 2007 & $9.7 \%$ & $18.2 \%$ & $27.4 \%$ & $7.3 \%$ & $14.7 \%$ & $23.6 \%$ \\
\hline 2008 & $11.2 \%$ & $22.0 \%$ & $31.1 \%$ & $11.5 \%$ & $22.5 \%$ & $32.2 \%$ \\
\hline 2009 & $13.2 \%$ & $24.0 \%$ & $37.0 \%$ & $13.3 \%$ & $24.6 \%$ & $37.9 \%$ \\
\hline 2010 & $23.2 \%$ & $31.9 \%$ & $44.1 \%$ & $23.9 \%$ & $33.5 \%$ & $46.6 \%$ \\
\hline 2011 & $11.0 \%$ & $21.6 \%$ & $35.9 \%$ & $18.7 \%$ & $34.2 \%$ & $51.0 \%$ \\
\hline \multicolumn{7}{|c|}{ Final Concert } \\
\hline 2007 & $9.9 \%$ & $20.3 \%$ & $30.2 \%$ & $6.3 \%$ & $15.5 \%$ & $24.4 \%$ \\
\hline 2008 & $10.8 \%$ & $19.2 \%$ & $31.6 \%$ & $9.3 \%$ & $18.7 \%$ & $30.9 \%$ \\
\hline 2009 & $17.1 \%$ & $25.2 \%$ & $36.5 \%$ & $14.9 \%$ & $24.0 \%$ & $35.8 \%$ \\
\hline 2010 & $21.6 \%$ & $31.4 \%$ & $47.1 \%$ & $19.9 \%$ & $31.5 \%$ & $47.7 \%$ \\
\hline 2011 & $13.2 \%$ & $18.7 \%$ & $29.5 \%$ & $20.1 \%$ & $29.4 \%$ & $37.3 \%$ \\
\hline
\end{tabular}


Table A.7 - Economic Impact (in $€$ ) of the minor concerts, of the Final Concert and of the Festival, due to greatly motivated tourists.

\begin{tabular}{|c|c|c|c|}
\hline minor concerts & Direct & Induced & Aggregate \\
\hline 2007 & 590.991 & 192.020 & 783.011 \\
\hline 2008 & 1.008 .126 & 338.590 & 1.346 .716 \\
\hline 2009 & 232.107 & 89.705 & 321.812 \\
\hline 2010 & 424.686 & 144.627 & 569.313 \\
\hline 2011 & 457.354 & 167.622 & 624.976 \\
\hline $\mathbf{2 0 0 7 - 2 0 1 1}$ & $\mathbf{2 . 7 1 3 . 2 6 4}$ & $\mathbf{9 3 2 . 5 6 4}$ & $\mathbf{3 . 6 4 5 . 8 2 8}$ \\
\hline Final Concert & Direct & Induced & Aggregate \\
\hline 2007 & 1.332 .858 & 399.845 & 1.732 .703 \\
\hline 2008 & 1.998 .502 & 621.911 & 2.620 .413 \\
\hline 2009 & 1.058 .895 & 388.240 & 1.447 .135 \\
\hline 2010 & 1.201 .775 & 424.760 & 1.626 .535 \\
\hline 2011 & 863.581 & 303.396 & 1.166 .977 \\
\hline $\mathbf{2 0 0 7 - 2 0 1 1}$ & $\mathbf{6 . 4 5 5 . 6 1 1}$ & $\mathbf{2 . 1 3 8 . 1 5 2}$ & $\mathbf{8 . 5 9 3 . 7 6 3}$ \\
\hline Festival & Direct & Induced & Aggregate \\
\hline 2007 & 1.923 .849 & 591.865 & 2.515 .714 \\
\hline 2008 & 3.006 .628 & 960.501 & 3.967 .129 \\
\hline 2009 & 1.291 .002 & 477.945 & 1.768 .947 \\
\hline 2010 & 1.626 .461 & 569.387 & 2.195 .848 \\
\hline 2011 & 1.320 .935 & 471.018 & 1.791 .953 \\
\hline $\mathbf{2 0 0 7 - 2 0 1 1}$ & $\mathbf{9 . 1 6 8 . 8 7 5}$ & $\mathbf{3 . 0 7 0 . 7 1 6}$ & $\mathbf{1 2 . 2 3 9 . 5 9 1}$ \\
\hline
\end{tabular}

Table A.8 - Economic Impact (in $€$ ) of the minor concerts, of the Final Concert and of the Festival, due to in part motivated tourists.

\begin{tabular}{|c|c|c|c|}
\hline minor concerts & Direct & Induced & Aggregate \\
\hline 2007 & 1.845 .474 & 615.874 & 2.461 .348 \\
\hline 2008 & 3.118 .998 & 1.056 .574 & 4.175 .572 \\
\hline 2009 & 1.521 .475 & 531.359 & 2.052 .834 \\
\hline 2010 & 1.598 .638 & 531.203 & 2.129 .841 \\
\hline 2011 & 1.634 .200 & 564.573 & 2.198 .773 \\
\hline $\mathbf{2 0 0 7 - 2 0 1 1}$ & $\mathbf{9 . 7 1 8 . 7 8 5}$ & $\mathbf{3 . 2 9 9 . 5 8 3}$ & $\mathbf{1 3 . 0 1 8 . 3 6 8}$ \\
\hline Final Concert & Direct & Induced & Aggregate \\
\hline 2007 & 1.355 .834 & 435.286 & 1.791 .120 \\
\hline 2008 & 3.762 .706 & 1.218 .106 & 4.980 .812 \\
\hline 2009 & 2.133 .818 & 713.132 & 2.846 .950 \\
\hline 2010 & 2.052 .400 & 696.509 & 2.748 .909 \\
\hline 2011 & 2.140 .097 & 700.138 & 2.840 .235 \\
\hline $\mathbf{2 0 0 7 - 2 0 1 1}$ & $\mathbf{1 1 . 4 4 4 . 8 5 5}$ & $\mathbf{3 . 7 6 3 . 1 7 1}$ & $\mathbf{1 5 . 2 0 8 . 0 2 6}$ \\
\hline Festival & Direct & Induced & Aggregate \\
\hline 2007 & 3.201 .308 & 1.051 .160 & 4.252 .468 \\
\hline 2008 & 6.881 .704 & 2.274 .680 & 9.156 .384 \\
\hline 2009 & 3.655 .293 & 1.244 .491 & 4.899 .784 \\
\hline 2010 & 3.651 .038 & 1.227 .712 & 4.878 .750 \\
\hline 2011 & 3.774 .297 & 1.264 .711 & 5.039 .008 \\
\hline $\mathbf{2 0 0 7 - 2 0 1 1}$ & $\mathbf{2 1 . 1 6 3 . 6 4 0}$ & $\mathbf{7 . 0 6 2 . 7 5 4}$ & $\mathbf{2 8 . 2 2 6 . 3 9 4}$ \\
\hline
\end{tabular}


Table A.9 - Discount factors for in part motivated tourists who would have not come if the Festival were not held.

\begin{tabular}{|c|c|c|c|c|c|c|}
\hline Festival Editions & 2007 & 2008 & 2009 & 2010 & 2011 \\
\hline \multicolumn{7}{|c|}{} \\
\hline minor concerts & 0.15 & 0.11 & 0.10 & 0.10 & 0.20 \\
\hline Final Concert & 0.06 & 0.10 & 0.10 & 0.13 & 0.14 \\
\hline
\end{tabular}

Table A.10 - Economic Impact (in $€$ ) of the minor concerts, of the Final Concert and of the Festival, due to in part motivated tourists who would have not come if the Festival were not held.

\begin{tabular}{|c|c|r|r|}
\hline minor concerts & Direct & Induced & Aggregate \\
\hline 2007 & 276.821 & 92.381 & 369.202 \\
\hline 2008 & 343.090 & 116.223 & 459.313 \\
\hline 2009 & 152.147 & 53.136 & 205.283 \\
\hline 2010 & 159.864 & 53.120 & 212.984 \\
\hline 2011 & 326.840 & 112.915 & 439.755 \\
\hline $\mathbf{2 0 0 7 - 2 0 1 1}$ & $\mathbf{1 . 2 5 8 . 7 6 2}$ & $\mathbf{4 2 7 . 7 7 5}$ & $\mathbf{1 . 6 8 6 . 5 3 7}$ \\
\hline Final Concert & Direct & Induced & Aggregate \\
\hline 2007 & 81.350 & 26.117 & 107.467 \\
\hline 2008 & 376.271 & 121.811 & 498.082 \\
\hline 2009 & 213.382 & 71.313 & 284.695 \\
\hline 2010 & 266.812 & 90.546 & 357.358 \\
\hline 2011 & 288.913 & 94.519 & 383.432 \\
\hline $\mathbf{2 0 0 7 - 2 0 1 1}$ & $\mathbf{1 . 2 2 6 . 7 2 8}$ & $\mathbf{4 0 4 . 3 0 6}$ & $\mathbf{1 . 6 3 1 . 0 3 4}$ \\
\hline Festival & Direct & Induced & Aggregate \\
\hline 2007 & 358.171 & 118.498 & 476.669 \\
\hline 2008 & 719.361 & 238.034 & 957.395 \\
\hline 2009 & 365.529 & 124.449 & 489.978 \\
\hline 2010 & 426.676 & 143.666 & 570.342 \\
\hline 2011 & 615.753 & 207.434 & 823.187 \\
\hline $\mathbf{2 0 0 7 - 2 0 1 1}$ & $\mathbf{2 . 4 8 5 . 4 9 0}$ & $\mathbf{8 3 2 . 0 8 1}$ & $\mathbf{3 . 3 1 7 . 5 7 1}$ \\
\hline
\end{tabular}

